\title{
Stem cell factor and mesenchymal and neural stem cell transplantation in a rat model of Huntington's disease
}

\author{
Kadiombo Bantubungi, a,b,c,*,1 David Blum, ${ }^{\text {b,c,1 }}$ Laetitia Cuvelier, ${ }^{\text {a }}$ Sabine Wislet-Gendebien, ${ }^{d}$ \\ Bernard Rogister, ${ }^{\mathrm{d}}$ Emmanuel Brouillet, ${ }^{\mathrm{e}}$ and Serge N. Schiffmann ${ }^{\mathrm{a}, *}$ \\ ${ }^{a}$ Laboratory of Neurophysiology, ULB-Erasme, 808 Route de Lennik, B-1070 Brussels, Belgium \\ ${ }^{\mathrm{b}}$ Inserm, U837, 1 Place de Verdun, 59045 Lille, France \\ ${ }^{\mathrm{c}}$ Université Lille 2, Faculté de Médecine, Institut de Médecine Prédictive et Recherche Thérapeutique, Jean-Pierre Aubert Research Centre, \\ Place de Verdun, 59045 Lille, France \\ ${ }^{\mathrm{d}}$ Center for Cellular and Molecular Neurobiology, University of Liege, Tour de Pathologie 2, CHU, Avenue de l'Hôpital, 1, 4000 Liege, Belgium \\ ${ }^{\mathrm{e}}$ Commissariat à l'Energie Atomique (CEA), Centre National de la Recherche Scientifique, Unite de Recherche Associée 2210 et Institut d'Imagerie \\ Biomoléculaire, CEA, 4 place du general Leclerc 91401 Orsay Cedex, France
}

Received 21 March 2007; revised 23 October 2007; accepted 2 November 2007

Available online 12 November 2007

\begin{abstract}
Neural and mesenchymal stem cells have been proposed as alternative sources of cells for transplantation into the brain in neurodegenerative disorders. However, the endogenous factors controlling their engraftment within the injured parenchyma remain ill-defined. Here, we demonstrate significant engraftment of undifferentiated exogenous mesenchymal or neural stem cells throughout the lesioned area in a rat model for Huntington's disease, as late as 8 weeks post-transplantation. We show that stem cell factor (SCF), strongly up-regulated within host cells in the damaged striatum, is able to activate the SCF receptor c-kit and its signaling pathway and to promote the migration and proliferation of mesenchymal and neural stem cells in vitro. Furthermore, c-kit receptor blockade alters neural stem cell distribution within the lesioned striatum. Host SCF expression is observed in atypical cells expressing glial fibrillary acidic protein and doublecortin in the lesioned striatum and in migrating doublecortin-positive progenitors. Taken together, these data demonstrate that SCF produced in situ in the lesioned striatum is an important factor in promoting the engraftment of stem cells within the lesioned brain. (C) 2007 Elsevier Inc. All rights reserved.
\end{abstract}

Keywords: Transplantation; Striatum; Stem cells; Huntington's disease; Stem cell factor; c-kit

\footnotetext{
* Corresponding authors. K. Bantubungi is to be contacted at Inserm, U837, 1 place de Verdun, 59045 Lille Cedex, France. Fax: +33 3206220 79. S.N. Schiffmann, Laboratory of Neurophysiology, ULB-Erasme, 808 Route de Lennik, B-1070 Brussels, Belgium.

E-mail addresses: Kadiombo.Bantubungi@lille.inserm.fr (K. Bantubungi), sschiffm@ulb.ac.be (S.N. Schiffmann).

${ }^{1} \mathrm{~KB}$ and DB equally contributed to this work.

Available online on ScienceDirect (www.sciencedirect.com).
}

\section{Introduction}

Stem cells are immature cells with the capacity for self-renewal that display the ability to differentiate into multiple mature cell types (Lindvall et al., 2004). The transplantation of stem cells or the mobilization of endogenous stem cells within the injured adult brain has been proposed as a potential therapy for neurological diseases (for reviews see Isacson, 2003; Tai and Svendsen, 2004).

Huntington's disease (HD) is a fatal inherited neurodegenerative disorder for which no treatment is yet available (Blum et al., 2003 and references herein). The transplantation of human fetal striatal tissue might serve as a useful therapeutic strategy and has led to encouraging results in clinical studies (Bachoud-Levi et al., 2000; Peschanski et al., 2004; Bachoud-Levi et al., 2006). However, adult stem cells such as mesenchymal stem cells (MSCs) and neural stem cells (NSCs) represent an attractive alternative. Although much information has been collected about the behavior and fate of fetal cells grafted into HD models (Kendall et al., 1998; Palfi et al., 1998; for reviews see Nakao and Itakura, 2000; Peschanski et al., 2004), less is known about the potential of stem cell transplantation.

A few studies have shown that pre-differentiated neural stem cells or growth factor-expressing stem cell lines confer behavioral benefits and/or cellular protection in phenotypic models of HD (Martinez-Serrano and Bjorklund, 1996; Kordower et al., 1997; Bosch et al., 2004; Ryu et al., 2004; McBride et al., 2004). Recently, it has also been demonstrated that environmental changes occurring during HD or following quinolinic acid (QA)-induced striatal lesions in a rat model reminiscent of HD (Beal et al., 1986; see also Guidetti et al., 2004) may stimulate in situ neurogenesis (Curtis et al., 2003; Tattersfield et al., 2004). Although the recruitment of endogenous neural stem cells in response to injury is clearly 
insufficient to compensate for progressive cell loss, it indicates that factors supporting the survival of stem cells are present within the lesioned area. However, the extent to which stem cells can migrate, survive and/or proliferate within the injured striatum, as well as the possible contribution of endogenous factors favoring their engraftment, remain pending questions. One such factor could be the stem cell factor (SCF), the ligand for the receptor c-kit. SCF has been shown to be a mitogen and chemoattractant for many cells in the hematopoietic system to enhance the mobilization of peripheral blood progenitor cells (McNiece and Briddell, 1995; Glaspy, 1996) and to play an important role in hematopoiesis, gametogenesis and melanogenesis (Williams and Lyman, 1991). The role of SCF in the nervous system is poorly understood. However, SCF has recently been shown to stimulate neurogenesis as well as the migration of endogenous neural progenitors in vivo (Jin et al., 2002; Sun et al., 2004). These data support that SCF could be an important factor in regulating the proliferation and recruitment of endogenous progenitor cells during brain injury.
A

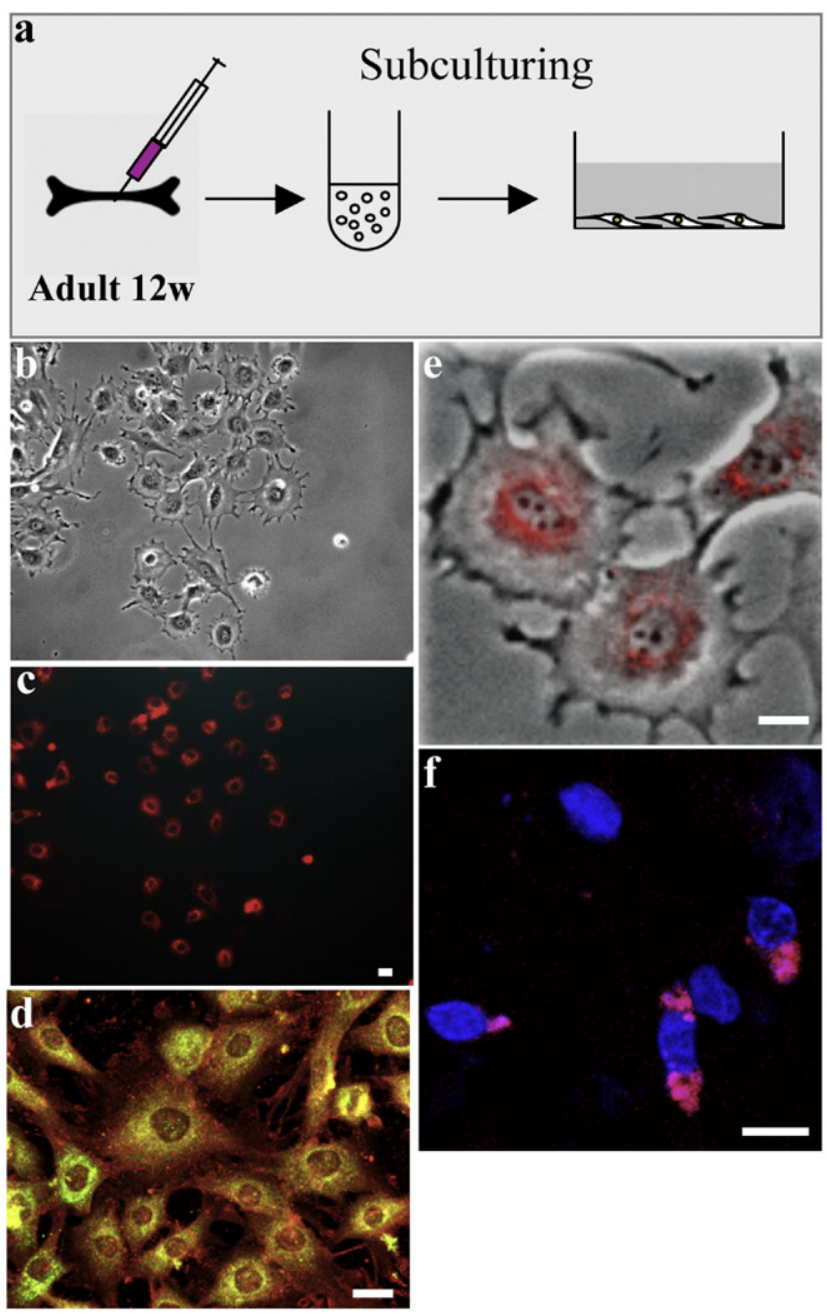

B

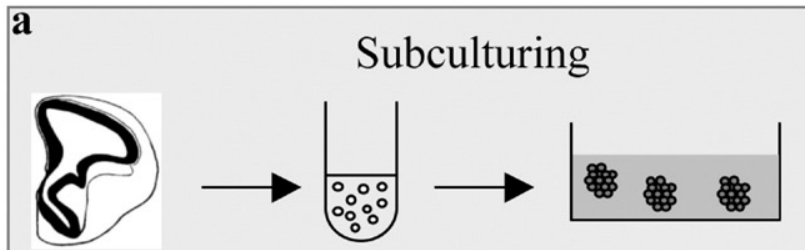

E17
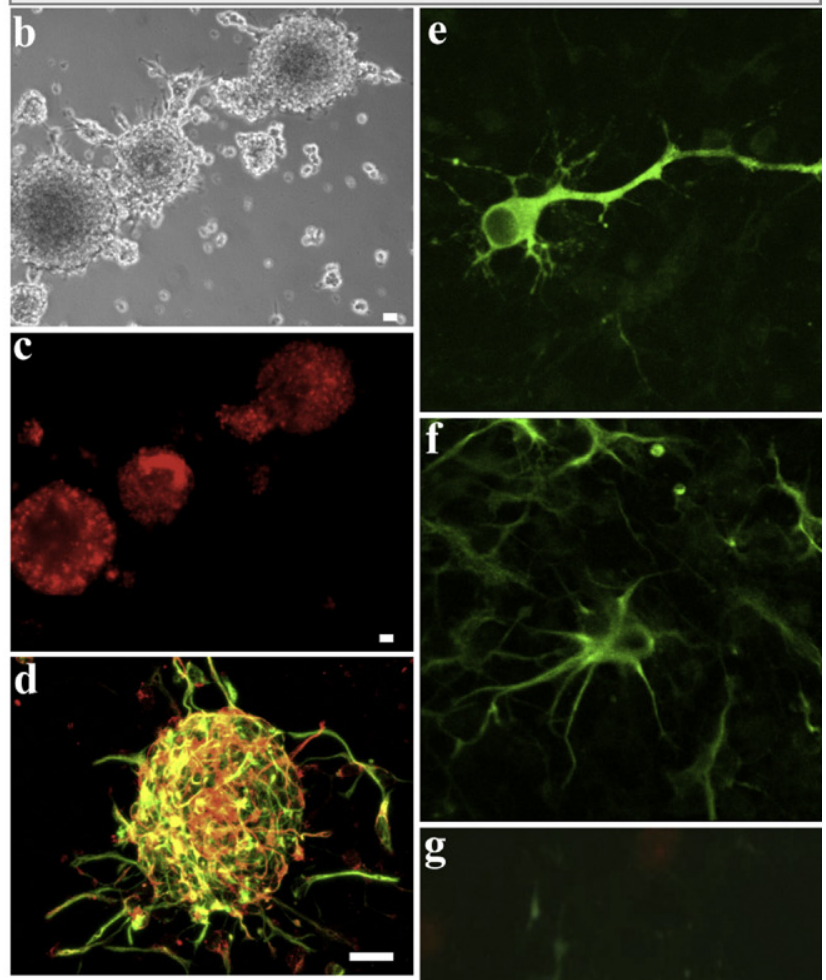

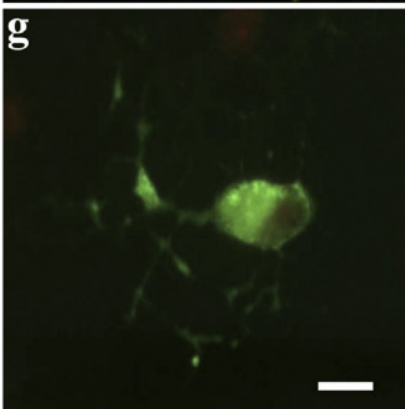

Fig. 1. Culture, pre-staining and characterization of rMSCs and rNSCs before transplantation. (Aa and $\mathrm{Ba}$ ) Schematic drawings representing the origin of rMSCs (bone marrow of $12 \mathrm{w}$ adult rat) and rNSCs (ganglionic eminence of E17 embryos), respectively. (Ab and Bb) Typical phase contrast morphology of rMSCs (Ab) and rNSCs $(\mathrm{Bb})$. (Ac and $\mathrm{Bc}$ ) Typical fluorescent pre-graft staining following PKH26 labeling of rMSCs (Ac) and rNSCs (Bc). (Ad and Bd) GFAP (red) and nestin (green) expression in pre-graft rMSCs (Ad) and rNSCs (Bd). Note that almost all cells coexpressed both markers. Similar GFAP expression was observed using both polyclonal and monoclonal antibodies. (Ae) In vitro perinuclear localization of PKH26 labeling in rMSCs before transplantation. (Af) In vivo perinuclear localization of PKH26 labeling (red) in the striatum of a rat grafted with rMSCs and sacrificed 3 weeks later. TOTO-3 iodide counterstaining is shown in blue. (Be-g) Phenotype of rNSCs following in vitro differentiation. Cells express MAP2 (Be), GFAP (Bf) or CNPase (Bg). Scale bars: Ab-d, Bb-d and $\mathrm{Be}-\mathrm{g}=20 \mu \mathrm{m}, \mathrm{Ae}-\mathrm{f}=5 \mu \mathrm{m}$. 
In the present study, we followed the fate of undifferentiated nestin-positive MSCs and NSCs grafted into the striatum following quinolinic acid (QA)-induced degeneration in a rat model of Huntington's disease. We observed that the pathological environment favors the engraftment of both cell types throughout the lesion core up to 2 months post-transplantation. The migration and/or proliferation of grafted cells within the degenerating striatum could depend, at least in part, on SCF produced in situ by atypical host cells expressing glial fibrillary acidic protein (GFAP), nestin and doublecortin (DCX), as well as by neural progenitors that migrate from the rostro-dorsal part of the subventricular zone (SVZ) to the lesion. Our observations strongly support the conclusion that (1) the local production of SCF by the host favors MSC or NSC engraftment within the striatum and (2) pathology-induced host gliosis and neurogenesis are active processes in this phenomenon.

\section{Results}

\section{rNSCs and rMSCs before transplantation}

Under the culture conditions chosen (Figs. 1Aa and Ba) and as previously shown (Reynolds and Weiss, 1992; Wislet-Gendebien et al., 2003, 2005), 99\% of the rMSCs and rNSCs used for transplantation were found to express the undifferentiated precursor marker nestin, as well as GFAP (Figs. 1Ad and Bd). The multipotential nature of rNSCs was demonstrated by their ability to differentiate into neurons, astrocytes and oligodendrocytes following epidermal growth factor (EGF) starvation and plating onto a coated surface (Figs. $1 \mathrm{Be}-\mathrm{g}$ ). As we have previously shown, rMSCs were capable of differentiating into adipocytes, chondrocytes and osteocytes (Wislet-Gendebien et al., 2003).

In order to identify the cells after transplantation, they were prelabeled with PKH26, a fluorescent lipophilic dye whose detection does not require immunostaining. As shown in Figs. 1A (b-c) and $\mathrm{B}(\mathrm{b}-\mathrm{c})$, all cells displayed PKH26 staining in vitro. Notably, PKH26 was localized at the perinuclear level in vitro (Fig. 1Ae). A similar localization was also observed in vivo, 3 (Fig. 1Af) and 8 weeks (not shown) following transplantation, in sections counterstained with the nuclear dyes TOTO-3 iodide (Fig. 1Af) or Sytox green (not shown). Importantly, the latter staining demonstrated that, at 3 weeks post-transplantation and later, the presence of PKH26 labeling in vivo was associated with intact and not shrunken nuclei, indicating that the grafted cells did not undergo massive cell death.

\section{Striatal lesion, time of transplantation and sacrifice}

In the protocol we used (Fig. 2A), rMSCs and rNSCs were grafted 1 week following striatal injection of QA (QA/rNSCs and $\mathrm{QA} / \mathrm{rMSCs}$ groups). Control animals were injected with vehicle alone (Vehicle/rNSCs and Vehicle/rMSCs groups). At this interval after QA injection, we have previously demonstrated the presence of striatal gliosis and inflammation characteristic of a pathologic environment, but without ventricular enlargement or striatal atrophy (Bantubungi et al., 2005). 4 weeks following QA injection, we observed significant ipsilateral striatal atrophy and enlargement of the lateral ventricle (Fig. 2B). At this time point, we still observed considerable gliosis, as characterized by a strong increase in the number of CD11b-positive microglial cells and GFAP-immunoreactive cells, as well as a massive loss of NeuN staining within the lesion core (see Fig. 9, Vehicle/DMEM vs. QA/DMEM animals).
A

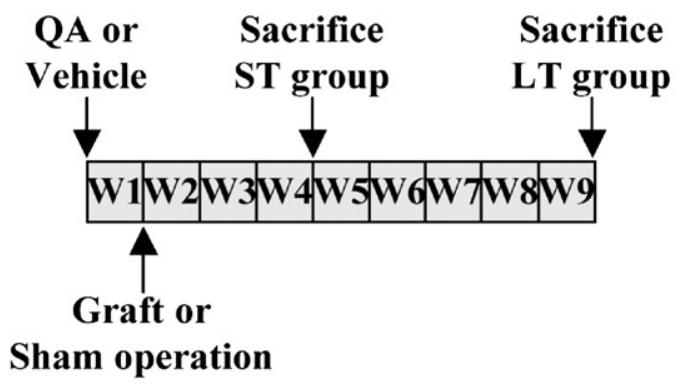

B

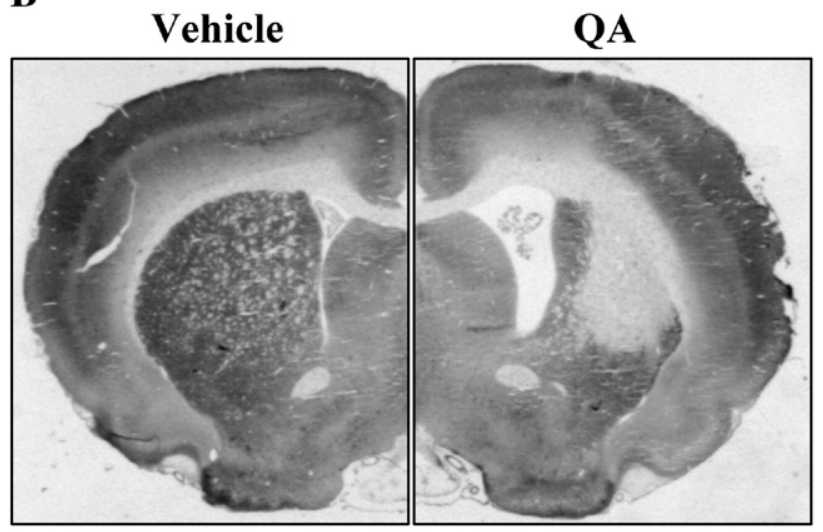

Fig. 2. (A) Schematic drawing representing the experimental protocol used for striatal lesions, stem cell transplantation and sacrifice of animals (ST: short-term, i.e., 3 weeks following transplantation $=4$ weeks following QA injection; LT: long-term, i.e., 8 weeks following transplantation $=9$ weeks following QA injection). (B) Typical cytochrome oxidase histochemical staining of striata injected with vehicle (left) or QA (right) 4 weeks after surgery. Note the absence of cytochrome oxidase activity within the lesion core after QA lesions as well as the striatal atrophy and ventricle enlargement in the QA-lesioned section (right) when compared to the control (left).

Very similar observations were made 9 weeks following lesion, whether or not the animals were subsequently grafted with rNSCs or rMSCs. These observations demonstrate the long-term persistence of a pathological environment in this model and support the view that the expression of CD11b and GFAP is related to the host and not the grafted cells.

\section{Distribution of engrafted rMSCs and rNSCs}

In order to estimate the impact of the degenerative environment on the distribution of transplanted stem cells within the lesioned striatum, we mapped cell distribution in a representative coronal plane (rostro-caudal plane bregma $+1 \mathrm{~mm}$ ) in vehicle and QAlesioned rats. In addition, we used serial sections to determine the rostro-caudal extent of the transplanted cells (see Experimental methods). As shown in Fig. 3, we observed a profusion of grafted cells within the lesioned area in QA-injected animals (Fig. 3A, upper panels), whereas few cells remained in vehicle-injected animals (Fig. 3A, lower panels) 3 weeks after transplantation, i.e., 4 weeks 
$\mathbf{A}$
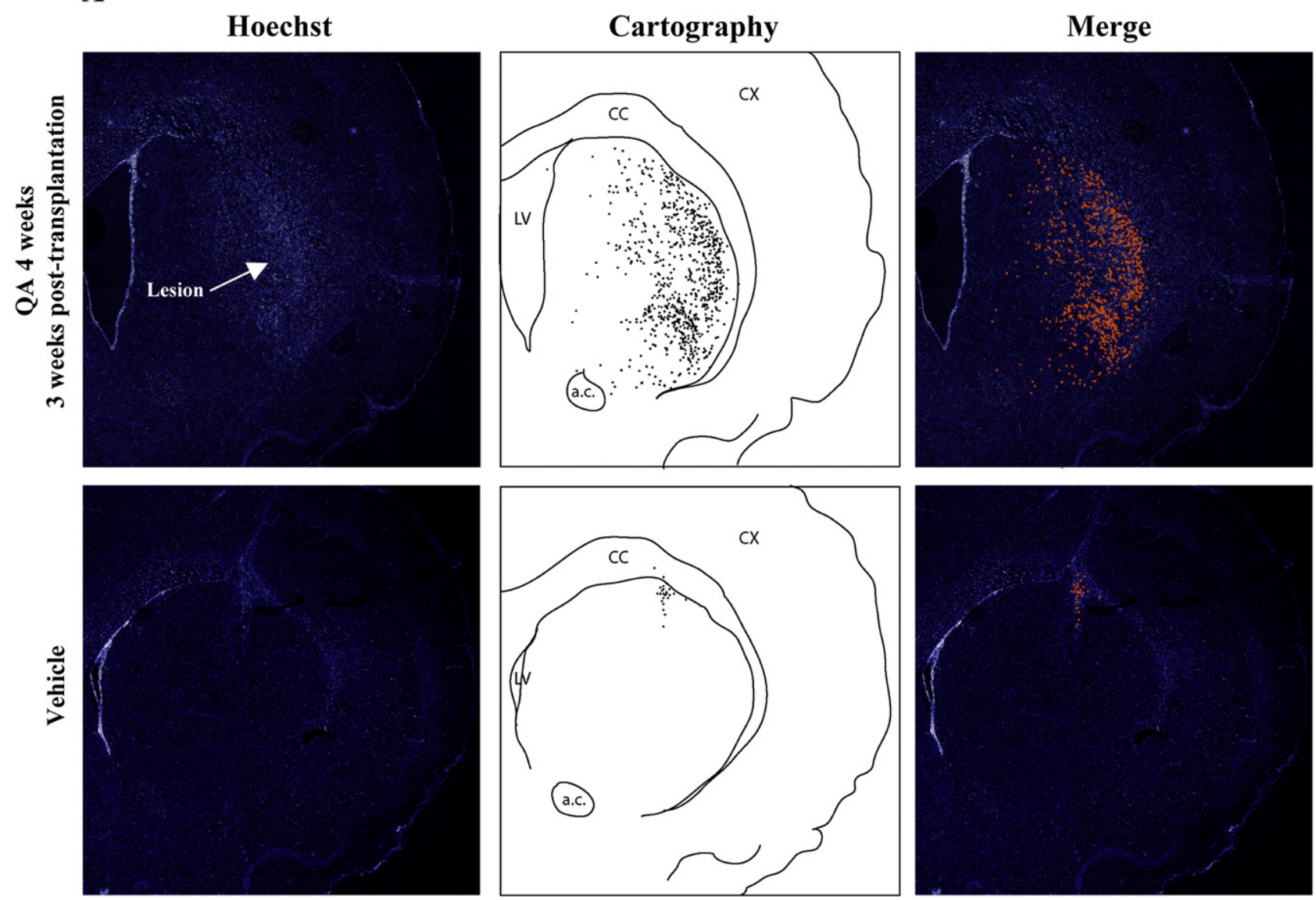

B

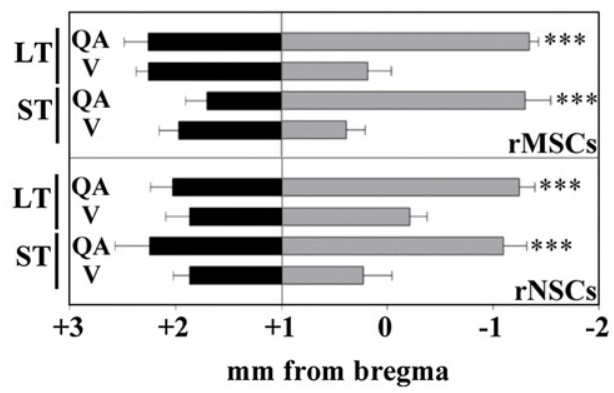

Fig. 3. (A) Representative distribution of rNSCs grafted into a QA-lesioned animal (upper panel) or a vehicle animal (lower panel) 3 weeks post-transplantation (i.e., 4 weeks post-lesion). For each panel, anatomical landmarks are represented using Hoechst counterstaining (left), cartography of cell distribution (middle) and merge (right). Similar observations were made for short- and long-term groups regardless of the cell type. Note the relative paucity of grafted cells in shamlesioned animals compared to their abundance in the lesioned striatum. The lesion is indicated by an arrow. CC: corpus callosum, LV: lateral ventricle, ac: anterior commissure, CX: cortex. (B) Occurrence of cells along the rostro-caudal axis of the striatum. Grafted cells can be readily seen throughout the length of the striatum in the QA-lesioned animals whereas their distribution is limited to the vicinity of the needle track in vehicle-injected rats (short term: ST=3 weeks posttransplantation; long term: LT $=8$ weeks post-transplantation). $* * * p<0.001$ as compared to vehicle-treated rats; one-way ANOVA followed by LSD post hoc test.

after lesion. It is worth noting that numerous cells were observed 3 days after transplantation into the sham-lesioned striatum (groups Vehicle/rNSCs or rMSCs; not shown), supporting that the normal or non-pathological environment did not favor the engraftment of cells. The average number of grafted cells within the lesioned striatum 3 weeks post-transplantation was estimated to be $158,271 \pm 24,025$ and $165,718 \pm 18,744$ for rNSCs and rMSCs, respectively. This provides further evidence for the long survival times of cells in the lesioned striatum, as well as their possible proliferation in vivo since the number of cells originally grafted was around 100,000 . The in situ proliferation of grafted cells was also demonstrated by the presence of numerous $\mathrm{PKH} 26$-positive cells displaying proliferating cell nuclear antigen (PCNA) immunoreactivity within the lesioned striatum (not shown). Finally, and in line, rMSCs and rNSCs were more extensively distributed within the QA-lesioned striatum at both short and long endpoints than unlesioned controls (Fig. 3B). Taken 
together, these data support the view that the lesioned environment favors the proliferation and intralesional distribution of both types of grafted stem cells. This effect was not transient or cell-specific since similar observations were made regardless of cell type (rMSCs and rNSCs) or post-transplantation time (3 weeks and 8 weeks; not shown).

To establish that the PKH26 labeling observed within the lesioned core corresponds to the presence of grafted cells and not to membrane fragments of dead cells taken up by neighboring resident cells such as microglia, we grafted stem cells that had been stained and killed by repeated freeze-thaw cycles (Supplemental data 1A) into QA-lesioned animals and compared their striatal distribution with that of grafted $\mathrm{PKH} 26$-positive living cells (Supplemental data 1B and C). Although the freeze-thaw cycles did not alter the fluorescence properties of PKH26, only a few fluorescent objects (probably auto-fluorescent red blood cells) were detected at the level of the injection site (Supplemental data 1B, lower panel) in animals grafted with killed cells and none resembling the PKH26-labeled cells seen after grafts of living cells (Supplemental data 1B, upper panel). At a more posterior level (Supplemental data 1C), almost all PKH26-related fluorescence disappeared when cells were killed prior to transplantation, further indicating that the PKH26 staining seen in our sections was mostly due to the presence of grafted cells. These results support the reliability of PKH26 dye "tagging" of migrating cells for the present application, in agreement with previous studies (Lim et al., 1997; Wichterle et al., 1999; Modo et al., 2002).

\section{Involvement of the stem cell factor}

Our topological observations suggest the existence of a factor produced by the lesioned striatum and capable of promoting the survival, proliferation and migration of both stem cell types within the lesion core following transplantation. SCF, the ligand for the receptor c-kit, was a good potential candidate as previous observations have indicated its pro-survival and chemoattractant properties with regard to different types of stem cells, including NSCs (Matsui et al., 1990; Erlandsson et al., 2004; Sun et al., 2004). Using immunohistofluorescence, we found that, in sham-lesioned animals (Vehicle/DMEM or Vehicle/grafts), SCF was expressed almost exclusively in the ependymal layer of the subventricular zone (SVZ; Fig. 4A), with a weak signal observed in the striatum (see higher magnifications in Figs. 9-11). Conversely, a strong increase in SCF expression was seen in the striatum of QA-lesioned animals 1 week post-lesion (i.e., at the time of transplantation; Fig. 4B) as well as at 3 (QA/DMEM animals; Figs. 4C and D) and 8 weeks (not shown) post-transplantation (i.e., 4 and 9 weeks post-lesion), although SVZ staining remained similar to controls (Figs. 4B-E). No increase in SCF expression was observed in the intact contralateral striatum (data not shown). The present observations thus demonstrate a long-lasting upregulation of host SCF within the striatum of QA-lesioned animals. The specificity of the SCF signal was ascertained by pre-incubating the antibody with the immunization peptide, which suppressed staining both within the SVZ and the lesion (Fig. 4F). Importantly, enhanced SCF expression could be
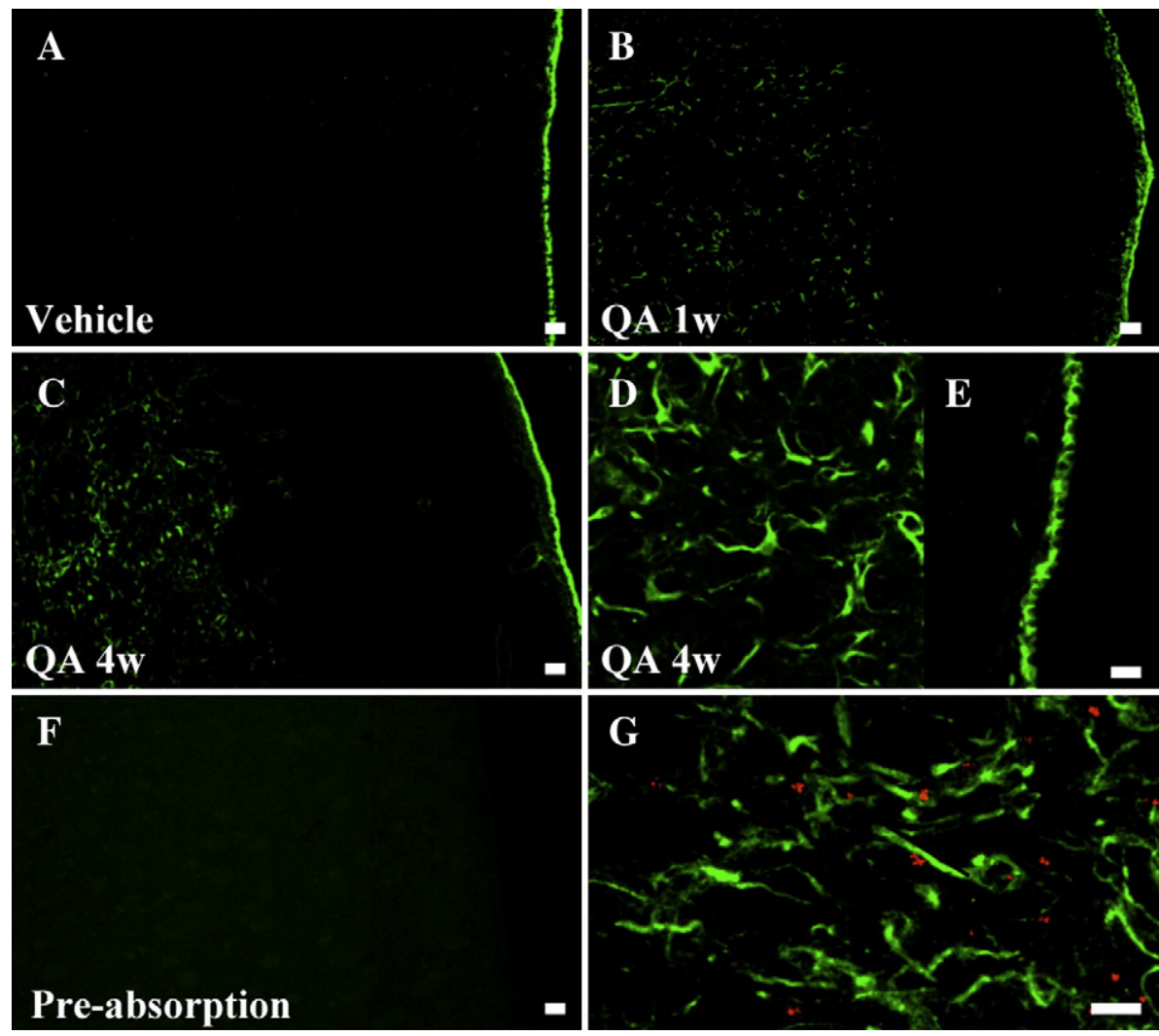

Fig. 4. Increase in SCF expression in the QA rat model. SCF expression detected by immunohistofluorescence in the striatum of vehicle-injected rat (A) or QAlesioned non-grafted rats 1 (B) and 4 (C-E) weeks post-injection. View at higher magnification at the level of the lesion core (D) and the SVZ (E). (F) Preincubation of the antibody with the immunization peptide abolishes staining both within the SVZ and the lesion. (G) Localization of PKH26-labeled rMSCs (red) in the lesion core presenting SCF immunoreactivity (green) 4 weeks post-lesion in QA/rMSCs rats. Note that similar observations were made for rNSCs (QA/ rNSCs groups) and that SCF expression was never observed in PKH26-positive cells. Scale bars: $\mathrm{A}-\mathrm{C}$ and $\mathrm{F}=50 \mu \mathrm{m} ; \mathrm{D}, \mathrm{E}$ and $\mathrm{G}=20 \mu \mathrm{m}$. 
detected all along the rostro-caudal axis of the striatal lesion (not shown). Furthermore, the localization of this sustained SCF immunoreactivity was in perfect accordance with the distribution of PKH26-positive cells in both long-term and short-term grafted animals (QA/rMSCs or QA/rNSCs groups; Fig. 4G). It is worth noting that the $\mathrm{PKH} 26$-positive grafted cells did not themselves express SCF in lesioned animals (QA/rNSCs or QA/rMSCs groups; Fig. 4G), and a similar pattern of SCF expression was observed in lesioned animals that did not receive transplants (QA/DMEM group). In contrast, striatal SCF expression was virtually absent in sham-lesioned grafted animals (Vehicle/rNSCs and Vehicle/rMSCs groups) as in the contralateral striatum of lesioned rats (see above). These observations support the conclusion that the SCF expression observed under lesion conditions (QA/rNSCs, QA/rMSCs and QA/ DMEM) was due uniquely to host cells.

We next decided to evaluate the potential functional activity of the SCF expressed by host cells in the lesioned striatum towards grafted stem cells. We examined the expression of the SCF receptor c-kit by rMSCs and $\mathrm{rNSCs}$, and its potential activation by recombinant SCF or proteins extracted from the striata of 4-week lesioned (non-grafted) rats, using biochemical and migration assays. As shown by western blotting, both cell types, as well as the SVZ dissected out from normal adult brains and used as a positive control (Jin et al., 2002), expressed c-kit (Fig. 5A). This expression was confirmed by pre-graft immunocytofluorescence in rMSCs and rNSCs (Figs. 5B and C). To evaluate the functional activation of c-kit in rMSCs and rNSCs, we exposed both cell types to recombinant rat SCF $(100 \mathrm{ng} / \mathrm{ml})$. As shown in Figs. 6A and $\mathrm{B}, \mathrm{SCF}$ triggered the activation of c-kit in both cell types, as demonstrated by an increase in the phospho-c-kit signal, and this consequently resulted in the phosphorylation of Erk. The SCF-c-kit pathway is well known as a promoter of migration in different types of stem cells such as hematopoietic (Hassan and Zander, 1996 for review), spermatogonial (Ohta et al., 2003) and neural stem cells (Jin et al., 2002; Erlandsson et al., 2004; Sun et al., 2004). We therefore examined the possibility that the activation of the c-kit pathway led to a similar functional effect, in addition to the increased kinase activity detected biochemically. Using Boyden chambers, we observed that $100 \mathrm{ng} / \mathrm{ml} \mathrm{SCF}$ induced the in vitro migration of both rMSCs and rNSCs by $24 \mathrm{~h}$. This effect was significantly decreased by pre-incubating the cells with a c-kit blocking antibody (Fig. 6C).

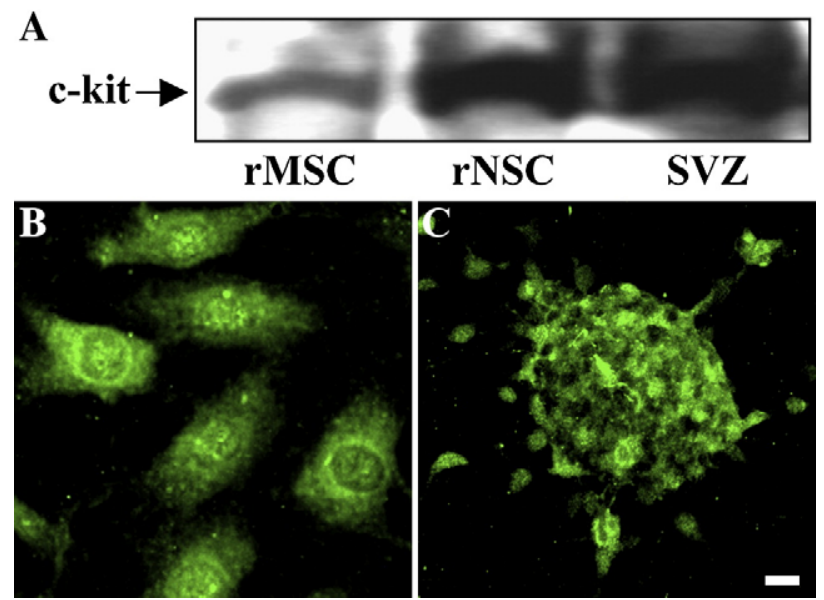

Fig. 5. Expression of c-kit as detected by western blotting (A) and immunocytofluorescence in rMSCs (B) and rNSCs (C). Scale bar $=10 \mu \mathrm{m}$.

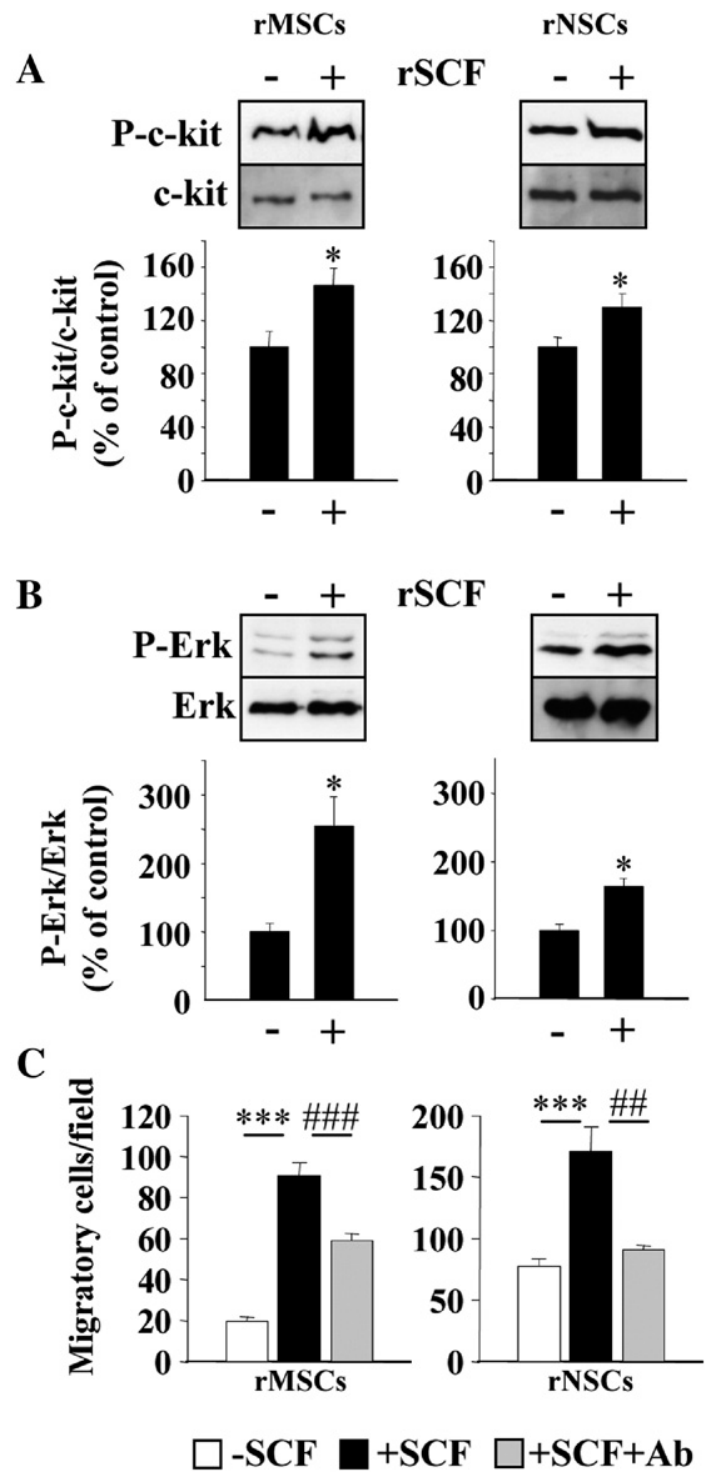

Fig. 6. Activation of c-kit and c-kit-induced in vitro migration in cultured rMSCs and rNSCs by recombinant SCF. (A) Effect of recombinant rat SCF (100 ng/ml) on c-kit phosphorylation (P-c-kit) in rMSCs (left) and rNSCs (right). (B) Effect of recombinant rat SCF $(100 \mathrm{ng} / \mathrm{ml})$ on Erk phosphorylation (P-Erk) in rMSCs (left) and rNSCs (right). Quantification is indicated below with controls set at $100 \%$. ${ }^{*} p<0.05$, *** $p<0.001$; one-way ANOVA followed by multiple comparison Bonferroni post hoc test. (C) In vitro migration of rMSCs (left) and rNSCs (right) following a 24-h stimulation with $100 \mathrm{ng} / \mathrm{ml}$ of recombinant SCF in the presence or absence of c-kit blocking antibody (Ab, $5 \mathrm{ng} / \mathrm{ml})$. ${ }^{* * *} p<0.001$; \#\#p $<0.001$; \#\#\#p $<0.001$; one-way ANOVA followed by multiple comparison Bonferroni post hoc test (groups being compared are indicated by horizontal bars).

In order to assess whether the SCF produced locally within the QA-lesioned striatum could similarly activate the c-kit signaling pathway and promote their in vitro migration, protein extracts from the injured (non-grafted) striatum were applied to both rMSCs and rNSCs. This produced the phosphorylation of c-kit and Erk in these cells, whereas protein extracts from control (vehicle-injected) striata had no effect (Figs. 7A, B). In addition, the incubation of cells with protein extracts from the QA-lesioned striatum significantly increased the in vitro migration of rMSCs (Fig. 7C, 

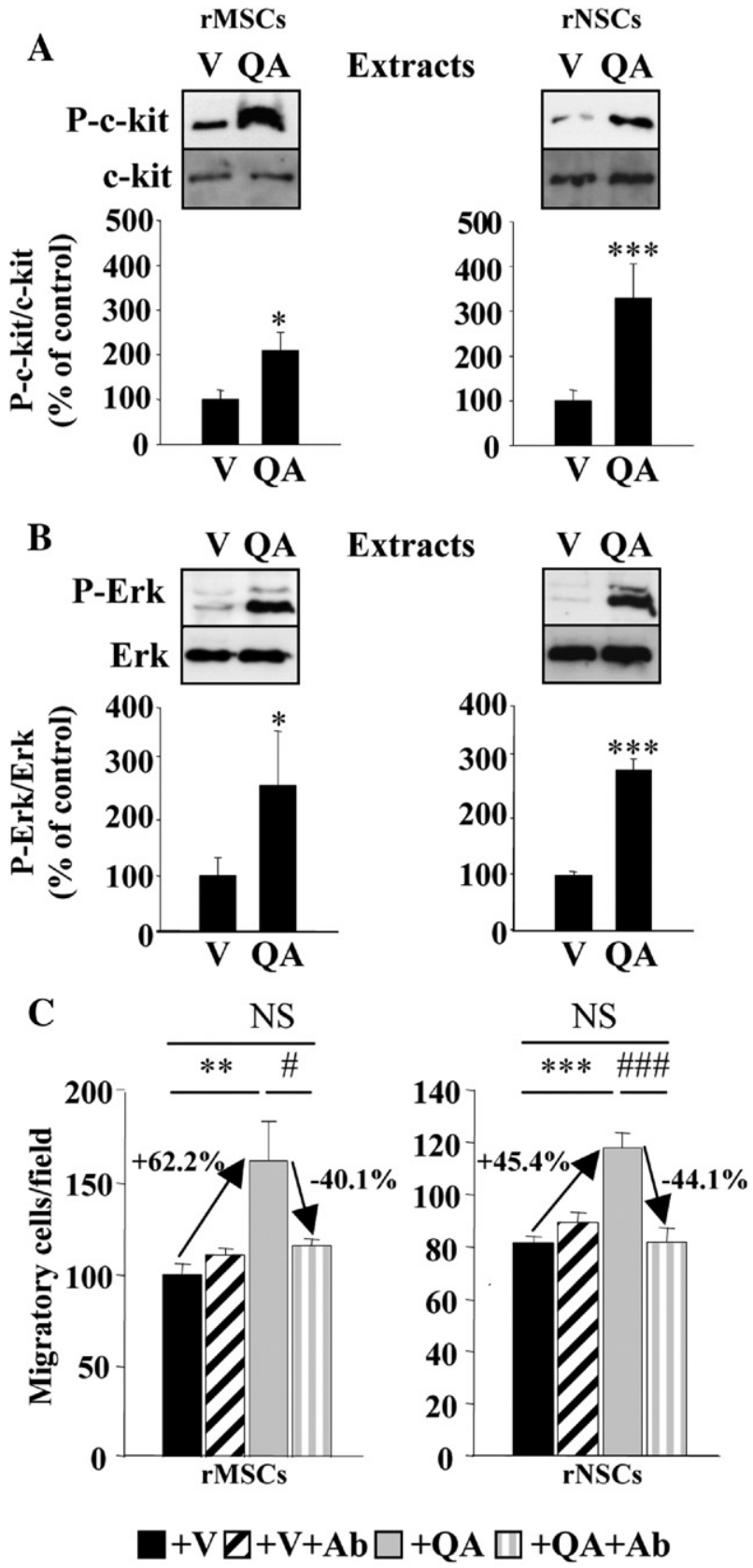

Fig. 7. Activation of c-kit and c-kit-induced in vitro migration in cultured rMSCs and rNSCs by protein extracts from the striata of vehicle-lesioned animals (V) or 4-week QA-lesioned animals (QA). (A) Effect of striatal extracts on c-kit phosphorylation (P-c-kit) in rMSCs (left) and rNSCs (right). (B) Effect of striatal extracts on Erk phosphorylation (P-Erk) in rMSCs (left) and rNSCs (right). Quantification is indicated below with controls set at $100 \% .{ }^{*} p<0.05$; ${ }^{* * *} p<0.001$. (C) In vitro migration of rMSCs (left) and rNSCs (right) following a 24-h stimulation with protein extracts from the striata of vehicle-lesioned animals (V) or 4-week QA-lesioned animals (QA) in the presence or absence of c-kit blocking antibody (Ab, $5 \mathrm{ng} / \mathrm{ml})$.

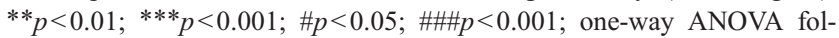
lowed by multiple comparison Bonferroni post hoc test (groups being compared are indicated by horizontal bars).

left) and rNSCs (Fig. 7C, right) by $62.2 \%$ and $45.5 \%$, respectively, when compared to an incubation with extract from non-lesioned striatum. Importantly, the c-kit blocking antibody reversed the migration promoted by QA extracts to near baseline levels (115.8 and $100.8 \%$ of the value for rMSCs and rNSCs treated with vehicleextract, respectively). The latter observation thus supports a role for locally produced SCF following QA lesioning in the migration of mesenchymal and neural stem cells within the striatum.

In addition to their intralesional migration, grafted cells may also proliferate, as suggested by our cell count and PCNA staining (see above). Given that SCF has been suggested to induce the proliferation of various cell types (McNiece and Briddell, 1995), it was thus possible that SCF influences the in situ proliferation of grafted cells. To test this possibility in vitro, we applied a low dose of recombinant SCF daily to our cells and measured their proliferation after 5 days. We found a small but statistically significant increase in the proliferation of rMSCs and rNSCs in the presence of the factor (Figs. 8A, B). Taken together, our data lead us to believe that the local production of SCF by host cells following striatal lesion promotes the proliferation of grafted neural stem cells, in addition to their migration.

Finally, we have estimated the role of endogenous SCF produced within the lesion core by grafting, in lesioned animals, rNSCs pre-treated for $6 \mathrm{~h}$ with a c-kit blocking antibody. As shown in Fig. 9, treatment with the c-kit blocking antibody modified the distribution of grafted cells along the antero-posterior axis. The number of rNSCs present at levels anterior to the injection site was decreased when cells were treated by the c-kit blocking antibody and there was no cell accumulation at the level of the graft core. These data suggest that c-kit receptor blockade might influence the survival and/or the proliferation of neural stem cells in vivo.

\section{Nature of SCF-expressing cells}

In order to determine the phenotype of SCF-positive cells in the host brain following striatal lesion, we performed double immunostaining using anti-NeuN, anti-CD11b and anti-GFAP
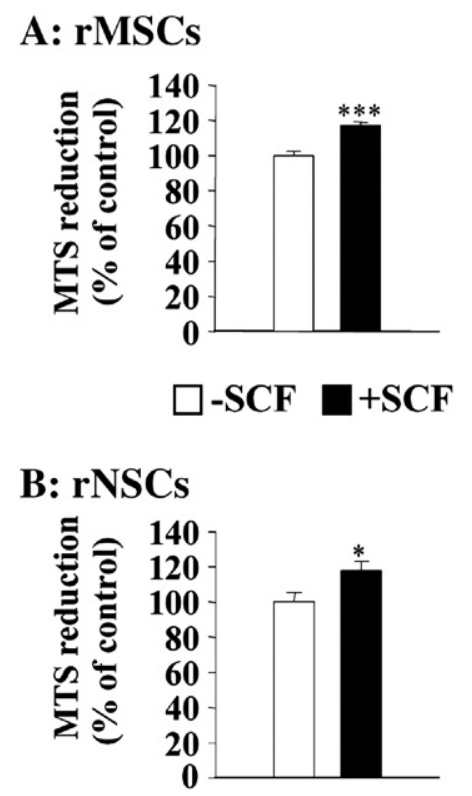

Fig. 8. Proliferation of rNSCs (A) and rMSCs (B) following a 5 day stimulation with $10 \mathrm{ng} / \mathrm{ml}$ of recombinant $\mathrm{SCF}$, as measured using an assay for MTS reduction (indicator of cell number). ${ }^{*} p<0.05$; ${ }^{* *} p<0.001$; oneway ANOVA followed by LSD post hoc test. 


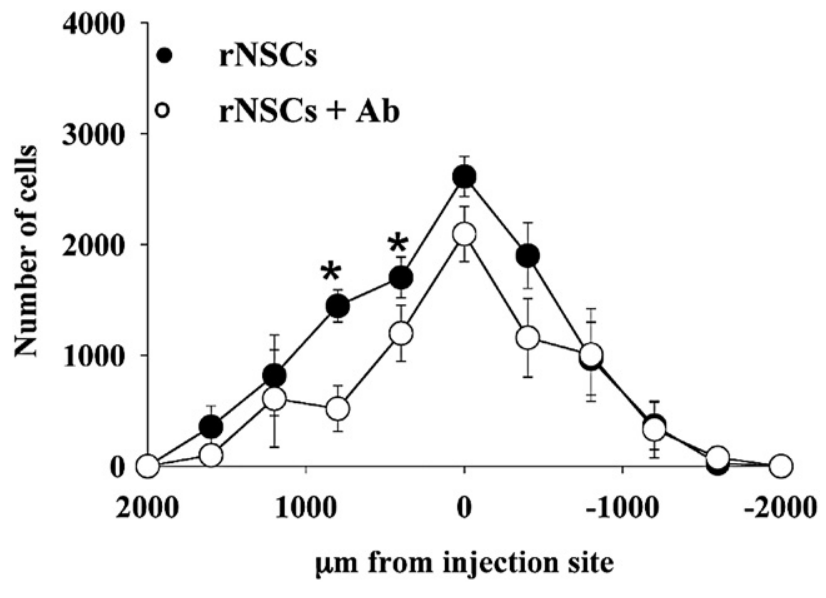

Fig. 9. Distribution of rNSCs within the lesion core of rats grafted with cells pre-treated or not with the c-kit blocking antibody $(\mathrm{Ab}) . * p<0.05$ vs. untreated cells.

antibodies in lesioned non-grafted animals (QA/DMEM). We observed that SCF was neither localized in the NeuN-positive neurons remaining at the lesion site nor in the activated CD11bpositive microglial cells (Figs. 10B and D). Conversely, numerous GFAP-positive cells exhibiting large cell bodies and thick processes displayed SCF expression within the lesioned area, and almost all the SCF-positive cells were also positive for GFAP (Fig. 10F). This colocalization was not limited to the lesioned area since we also observed GFAP+/SCF+ cells within the dorso-lateral part of the subventricular zone (SVZ; Supplemental data 2). Notably, GFAP+/SCF+ staining could also be observed, although to a lesser extent, in the dorso-lateral SVZ of vehicle-treated unlesioned rats. Similar observations were made when SCF/S100 $\beta$ double staining was performed (not shown). These data support the possibility that SCF is expressed by a sub-population of host astroglial cells following striatal lesion.

When we checked the topology of SCF staining, we observed that the density of host cells expressing SCF within the dorsal subventricular zone (dSVZ) at anterior striatal levels was strongly increased in animals in the short- (Fig. 11B) and long-term lesioned groups (not shown) when compared with controls (Fig. 11A). Doublecortin (DCX) immunostaining revealed that the increased SCF staining within the dSVZ was accompanied by an increase in thickness as well as a change in the axis of the latter (Fig. 11B; see arrows and Supplemental data 3), suggesting an increase in the production of neural progenitors in order to reach the lesion. In accordance with this view, within the dSVZ (Fig. 11B) as well as in the intermediate zone extending from the dSVZ to the lesion (Fig. 11C; see Supplemental data 3 for a low magnification view), many DCX-labeled cells displayed the morphological features of migrating neuroblasts, with elongated leading processes. These changes were not observed in 1-week lesioned animals (not shown), supporting the occurrence of a progressive increase in neurogenesis and progenitor migration in the QA model. In both the areas mentioned above, many DCXpositive cells co-expressed SCF in 4-week QA-lesioned animals, whereas few double-labeled cells were observed in controls, suggesting that a fraction of the SCF-expressing cells might be progenitors migrating from the dSVZ. Increased DCX immunoreactivity was also found within the lesion site (Fig. 11E). Interestingly, a substantial number of striatal DCX-positive cells were labeled with the anti-SCF antibody (Fig. 11E). Given our previous GFAP and S100 $\beta$ immunolabeling results, these observations suggest that cells that express SCF could be simultaneously positive for DCX, GFAP and S100 $\beta$. This view was supported by other double and triple immunolabeling studies. In the lesion core, DCX-positive cells presented the large cell bodies and thick processes seen with $\mathrm{SCF}+/ \mathrm{GFAP}+$ cells (see Figs. $10 \mathrm{~F}$ and $11 \mathrm{E}$ ). Using GFAP/DCX double labeling, we observed that, in the lesion, such DCX-positive cells strongly co-expressed GFAP (Fig. 12B) whereas these markers were not colocalized either within the dSVZ (Supplemental data 4) or the rest of SVZ (not shown). Similar observations were made following double DCX/S100 $\beta$ staining (Supplemental data 5). Substantial co-expression of SCF, GFAP and DCX within the same cells was confirmed by triple labeling (Fig. 12C). Finally, we found that DCX-positive cells also coexpressed nestin (Fig. 12E), suggesting that SCF-expressing cells within the lesion may represent a mix of atypical reactive astrocytes and neuronal progenitors. Accordingly, the majority of GFAP-positive cells exhibiting thick processes were stained for nestin (not shown).

\section{Discussion}

Endogenous neural progenitors have the ability to proliferate and/or migrate towards brain lesions in various pathological models as well as in the diseased human brain (Arvidsson et al., 2002; Curtis et al., 2003; Sun et al., 2004; Tattersfield et al., 2004). Exogenous stem cells also display an ability to migrate and survive in the lesioned parenchyma following transplantation (Eglitis et al., 1999; Mahmood et al., 2001; Imitola et al., 2004; Hill et al., 2004). However, little is known about the factors controlling these events and the potential of endogenous progenitors to favor the engraftment, migration and proliferation of exogenous progenitors.

Our results show that rMSCs and rNSCs display a similar distribution once grafted within the sham-lesioned or lesioned brain. In a normal environment, even though cells could be detected in the striatum at very short time intervals after grafting, few were present in this region 3 or 8 weeks after transplantation. Conversely, when cells were grafted following an excitotoxic insult, they were massively present and distributed throughout the lesioned structure. Our observations are also in accordance with the general view that the environment of the diseased brain promotes the survival and migration of grafted stem cells (see Bjorklund and Stenevi, 1984; Sotelo and Alvarado-Mallart, 1987 but also Watts and Dunnett, 1998; Eglitis et al., 1999; Nishino et al., 2000; Mahmood et al., 2001; Imitola et al., 2004; Hill et al., 2004; Kelly et al., 2004; Geloso et al., 2007) and lead us to suggest that at least one factor present within the lesion core promotes the engraftment of these two types of exogenous stem cells of distinct embryonic origins. One such factor could be SCF, shown to be mitogen and chemoattractant for many cells in the hematopoietic system, with the ability to enhance the mobilization of peripheral blood progenitor cells (McNiece and Briddell, 1995; Glaspy, 1996) and to stimulate neurogenesis as well as the migration of endogenous neural stem cells in vivo (Jin et al., 2002; Sun et al., 2004). Indeed, from 1 to 9 weeks post-lesion, we found a strong increase in SCF expression, restricted to the site of stem cell engraftment within the striatum. SCF is known to activate its receptor, c-kit, stimulating receptor autophosphorylation and downstream signaling pathways that involve phosphatidylinositol-3-kinase, Src, JAK/STAT and/or MAP kinases (Linnekin, 1999; Wandzioch et al., 2004). c-kit is 

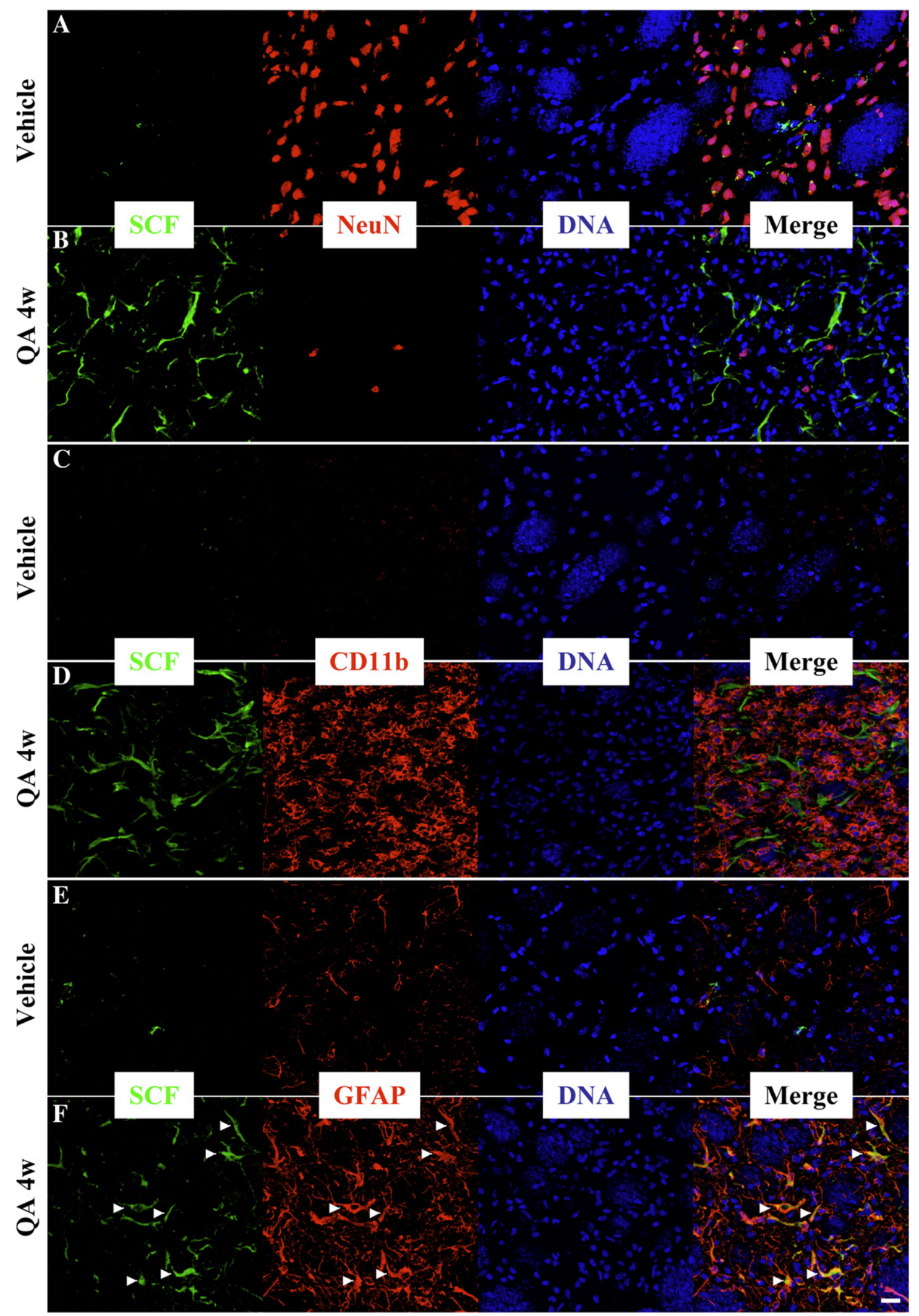

Fig. 10. Absence of SCF in mature neurons and microglial cells in the lesion core. SCF (green) does not colocalize with NeuN (red in A, B) or CD11b (red in C, D) in Vehicle/DMEM animals (A, C) or in 4-week QA-lesioned animals (QA/DMEM group; B, D). SCF (green) did colocalize with GFAP (red) in lesion core of QA-injected animals (F). No colocalization is seen in the control striatum (E). TOTO-3 iodide nuclear counterstaining is shown in blue. Scale bar $=20 \mu \mathrm{m}$. Staining patterns were similar regardless of whether the animals received rMSCs or rNSCs (Vehicle/rMSCs or rNSCs and QA/rMSCs or rNSCs), demonstrating that the staining seen following QA lesions is of host origin. 

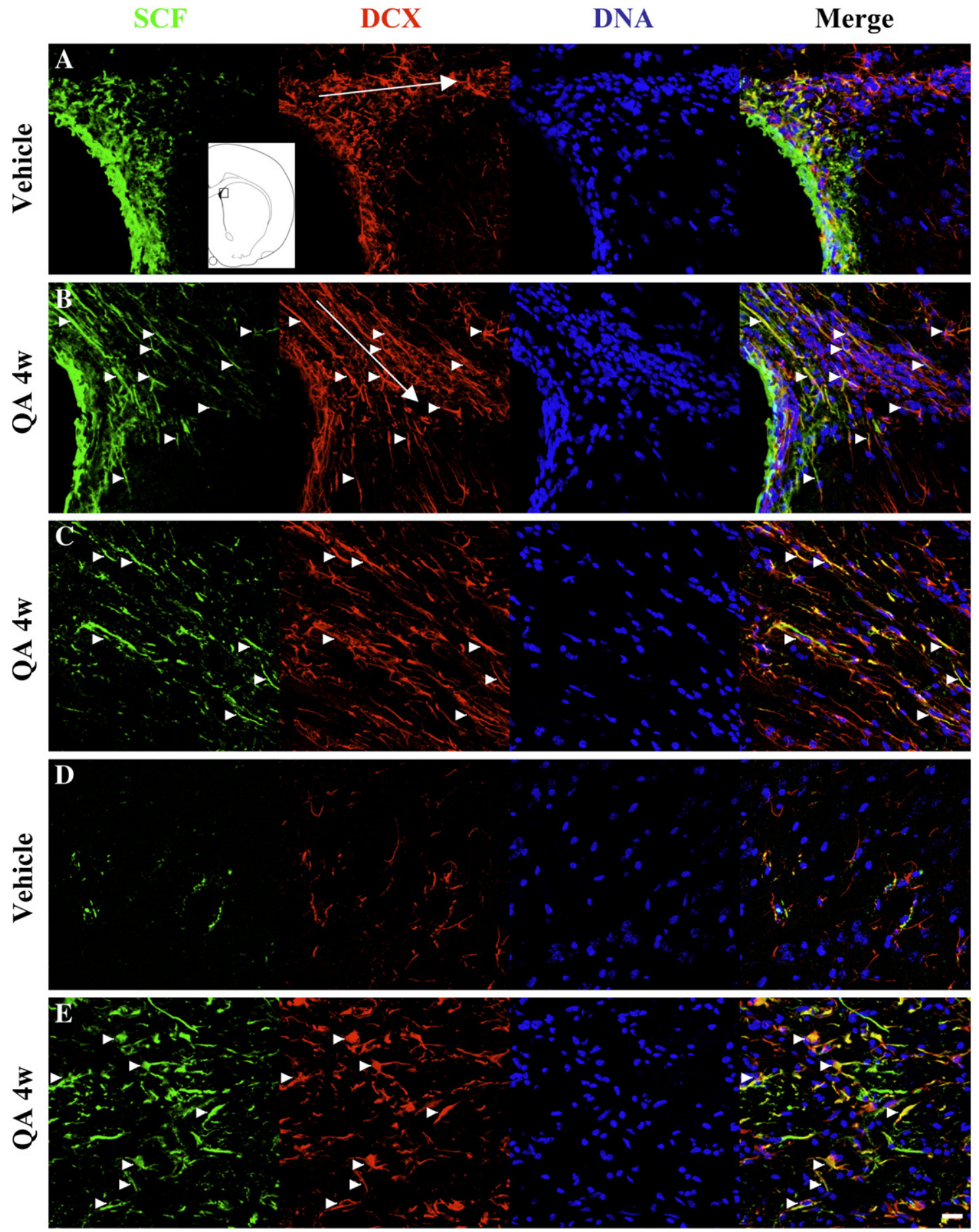

Fig. 11. SCF is expressed by neural progenitors following QA lesion. Colocalization of SCF (green) with DCX (red) in coronal sections from Vehicle/DMEM animals (A, D) and 4-week QA-lesioned animals (QA/DMEM group; B, C, E). Following QA lesion, expression of SCF and DCX is increased within the dorsolateral part of the SVZ where many cells express both markers (B; control animal shown in A; inset in A indicates where photomicrographs were taken). Arrows represent the general axis of the dorso-lateral part of the SVZ. Colocalization also occurs in the area between the rostral migratory stream and the lesion core (C). (E) Most SCF-expressing cells in the striatal lesion coexpress DCX. (D) Striatum of a control rat. Results were similar for 8-week QA-lesioned animals. TOTO-3 iodide nuclear counterstaining is shown in blue. Scale bar $=20 \mu \mathrm{m}$. Staining patterns were similar regardless of whether the animals received rMSCs or rNSCs (Vehicle/rMSCs or rNSCs and QA/rMSCs or rNSCs) demonstrating that the staining observed following QA lesions is of host origin.

expressed not only by rNSCs as previously suggested (Sun et al., 2004) but also by the nestin-positive rMSCs used in our study. In line with this observation, we demonstrated that the c-kit signaling pathway could be activated by recombinant SCF within these cells. Moreover, protein extracts from QA-lesioned striata were also able to activate the c-kit signaling pathway within rMSCs and rNSCs, 
indicating that the SCF produced within the lesion site is functional and can stimulate the grafted cells. In addition, we found that both recombinant SCF and striatal extracts from lesioned animals promote the migration of rMSCs and rNSCs in vitro. These observations agree with recent studies reporting that Erk activation is associated with the homing of NSCs promoted by SDF-1 $\alpha$ within the ischemic brain (Imitola et al., 2004) and the pro-survival and promigratory effect of SCF towards NSCs (Jin et al., 2002; Erlandsson
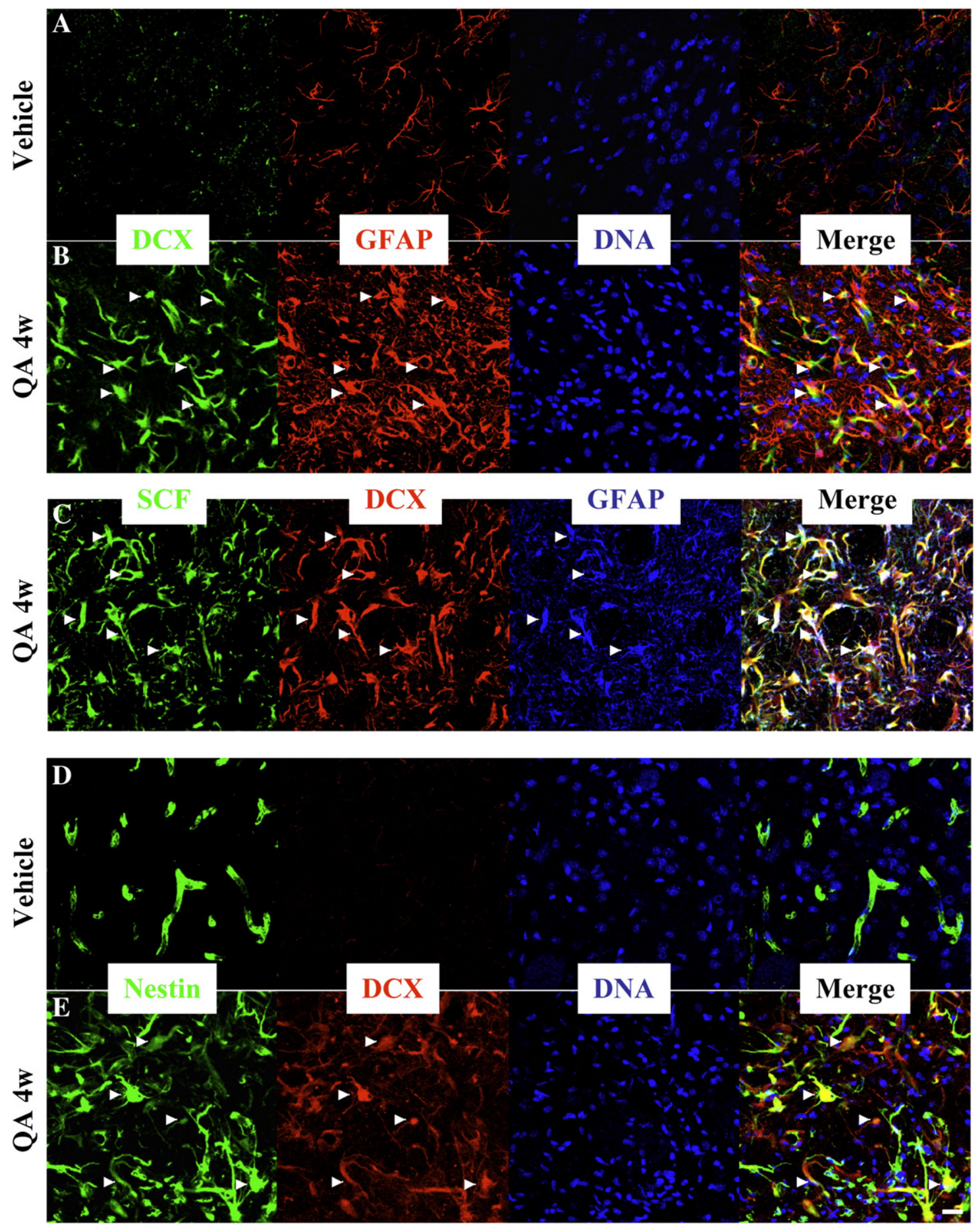

Fig. 12. Presence of atypical DCX/GFAP/SCF-expressing cells within the lesion core. Colabeling of DCX (green) with GFAP (red) in Vehicle/DMEM animals (A) and 4-week QA-lesioned animals (QA/DMEM group; B). (C) Triple SCF (green)/DCX (red)/GFAP (blue) labeling within the lesion core of 4-week QAlesioned animals (QA/DMEM). Costaining of Nestin (green) and DCX (red) in Vehicle/DMEM animals (D) and 4-weeks QA-lesioned animals (QA/DMEM). TOTO-3 iodide nuclear counterstaining is shown in blue in A, B, D and E. Scale bar $=20 \mu \mathrm{m}$. Note that in A and B, a monoclonal GFAP antibody was used whereas in D and E, a polyclonal one was used. Staining patterns were similar regardless of whether the animals received rMSCs or rNSCs (Vehicle/rMSCs or rNSCs and QA/rMSCs or rNSCs) demonstrating that the staining observed following QA lesions is of host origin. 
et al., 2004; Sun et al., 2004). Also, as previously shown for other cell types (McNiece and Briddell, 1995), we obtained in vivo (our cell counts and PCNA staining) and in vitro (MTT assay) data showing that SCF significantly increased the proliferation of stem cells. Finally, in line with recent in vitro observations (Erlandsson et al., 2004), we obtained in vivo data suggesting that the blockade of ckit receptor prior transplantation alters the proliferation/survival of rNSCs. Taken together, our results indicate that SCF produced within the lesioned striatum may contribute to the migration, survival and proliferation of stem cells following transplantation. Besides SCF, other factors could be involved. Indeed, the injection of TGF $\alpha$ into the dopamine-denervated striatum promote the migration of adult neural progenitors from the subventricular zone (Cooper and Isacson, 2004); the ciliary neurotrophic factor (CNTF) promotes the differentiation and thus the survival of exogenous stem cells in the QA-lesioned environment (McBride et al., 2004); the chemokine SDF-1 $\alpha$, which is upregulated following QA injection (Croitoru-Lamoury et al., 2003) as well as other chemokines (Belmadani et al., 2006), has been shown to direct the migration of neural stem cells and to promote the homing of bone marrow stem cells following hypoxia/ischemia (Imitola et al., 2004; Hill et al., 2004).

The increased SCF expression detected in our QA-lesioned rats was not due to neuronal or microglial production since we did not observe co-labeling with NeuN or CD11b. This negative observation does not however rule out the possibility that the important microglial reaction present in the lesioned striatum influences the expression of SCF by surrounding cells. Strikingly, we found that most SCFpositive cells also expressed DCX. This is true for the dSVZ and extends up to the lesion core, where strong DCX upregulation can be seen. The expression of DCX, a marker for migrating neuronal progenitors, is an indication of neurogenesis as in the adult brain, within areas of continuous neurogenesis (Brown et al., 2003), or in case of increase in brain neurogenesis induced by environmental factors or insults (Couillard-Despres et al., 2005). Such an increase in neurogenesis following QA injection is in line with previous findings (Tattersfield et al., 2004; Collin et al., 2005). Our data thus support the view that SCF is produced, at least in part, by neural progenitors that migrate from the dorsal subventricular zone.

Increased neurogenesis is a common feature of various neurological conditions such as stroke, Alzheimer's disease and Huntington's disease (Curtis et al., 2003; Kokaia and Lindvall, 2003; Jin et al., 2004). However, its exact functional consequence remains unclear (Emsley et al., 2005) as the recruitment of endogenous neural stem cells is clearly insufficient to compensate for the progressive cell loss that occurs. SCF-expressing cells were strongly co-labeled with GFAP and S100 $\beta$, suggesting that this factor may also be released by atypical DCX-expressing astroglial cells present in the lesion core. It is also worth mentioning that neural progenitor cells co-expressing the neuronal and glial markers, GFAP, nestin and $\beta$ III-tubulin have been recently characterized in the human fetal brain (Rieske et al., 2007). Ultimately, pathology-induced events such as neurogenesis and gliosis may promote the in situ delivery of factors important for stem cell engraftment and migration and are thus crucial for cell-based therapeutics. In this way, the local delivery of factors such as SCF, possibly by the grafted stem cells themselves, may increase their clinical potency. Furthermore, as supported by recent data, SCF delivery may also provide additional protective effects against excitotoxic neuronal death (Dhandapani et al., 2005) that plays a major role in various neurological conditions (Greene and Greenamyre, 1996).

\section{Experimental methods}

Mesenchymal stem cell cultures

Rat mesenchymal stem cells (rMSCs) were obtained from 12-week-old adult Wistar rat bone marrow as we have previously described (WisletGendebien et al., 2003, 2005; Fig. 1Aa). Between 100 and $200 \times 10^{6}$ marrow cells were plated in T75 tissue culture flasks in DMEM/10\% fetal bovine serum (Invitrogen, Belgium). After $24 \mathrm{~h}$, non-adherent cells were removed by renewing the medium. When the rMSCs reached confluence, they were resuspended in $0.25 \%$ trypsin and $1 \mathrm{mM}$ EDTA and sub-cultured. To initiate nestin expression, 10 passages (which correspond to 25 population doublings) of rMSCs were grown in DMEM/F12 medium (WisletGendebien et al., 2003). Cells were then prepared for transplantation, activity and migration tests or mounted on poly-ornithine-coated coverslips for immunocytofluorescence as described below.

Neural stem cell cultures

Rat neural stem cells (rNSCs) were obtained from the lateral (LGE) and medial ganglionic eminences (MGE) of 17- to 18-day-old Wistar rat embryos and prepared as described (Reynolds and Weiss, 1992; Fig. 1Ba). For dissociation, plating and maintenance, we used DMEM/F12 (1:1, v/v) complemented by B27 and N2 (Invitrogen, Belgium) in the presence of $20 \mathrm{ng} / \mathrm{ml}$ of epidermal growth factor (EGF; Sigma, Belgium). Briefly, the brain and meninges were removed. The LGE and MGE were carefully dissected out and mechanically dissociated in the culture medium by trituration with a polished Pasteur pipette. Once dissociated and counted using Trypan blue, viable cells were seeded at $2 \times 10^{5}$ cells $/ \mathrm{ml}$ in uncoated T75 tissue culture flasks. Cells proliferated and formed spheres in suspension. Half the serum-free medium was renewed after 2 days. Ten days after plating, primary neurospheres were mechanically dissociated into single cells. Three days after the passage, cells were prepared for transplantation, activity and migration tests or mounted on poly-ornithinecoated coverslips for immunocytofluorescence as described below.

\section{Preparation of cells before transplantation}

rMSCs (passage 10 or more) and rNSCs (at passage 2) were labeled with $\mathrm{PKH} 26,72 \mathrm{~h}$ before transplantation. $\mathrm{PKH} 26$, a non-toxic fluorescent lipophilic dye (Ashley et al., 1993), was added to the cultures at a concentration of $4 \mu \mathrm{M}$ according to the manufacturer's instructions (Sigma, Belgium). This protocol resulted in the labeling of all cells in vitro (Figs. 1Ac and $\mathrm{Bc}$ ).

\section{Pre-graft immunocytofluorescence}

To characterize the phenotype of rMSCs and rNSCs prior to transplantation, a subset of cells mounted on poly-ornithine-coated coverslips were fixed with $4 \%$ paraformaldehyde for $20 \mathrm{~min}$ at room temperature and washed 3 times in 0.01 M PBS. Non-specific binding was blocked by a 1-hour incubation in $0.01 \mathrm{M}$ PBS containing $10 \%$ normal horse serum and $0.1 \%$ Triton. The cells were incubated overnight at $4{ }^{\circ} \mathrm{C}$ with rabbit polyclonal anti-GFAP (1/1000, G9269, Sigma, Belgium), mouse monoclonal anti-nestin (1/1000, rat401, Pharmingen, USA), rabbit polyclonal anti-MAP2 (1/1000, a gift from JP Brion, Brussels, Belgium), mouse monoclonal anti-CNPase (1/1000; C5922, Sigma, Belgium) or goat polyclonal anti-c-kit (1/1000, sc-1494, Santa-Cruz, USA) primary antibodies (diluted in $0.01 \mathrm{M}$ PBS). After three washes, the cells were incubated in biotinylated donkey anti-mouse IgG, anti-rabbit $\operatorname{IgG}$ or anti-goat $\operatorname{IgG}(1 / 200$, Jackson ImmunoResearch, USA) for $1 \mathrm{~h}$ at room temperature. After washing, the cells were incubated in FITC or Cy-3 conjugated with streptavidin (1/200, Vector Laboratories, USA) for $1 \mathrm{~h}$ at room temperature. All preparations were mounted with a SlowFade Light anti-fade kit (Molecular Probe, USA) and observed using a laser-scanning confocal microscope (see below). 
Striatal lesions and transplantation procedure

QA lesions and transplantations were performed on adult male Wistar rats (225-250 g, Charles River, Belgium). Animals were housed four per cage with food and water ad libitum and maintained in a temperature- and humidity-controlled room with a $12 \mathrm{~h}$ light/dark cycle. The number of animals used was kept to a minimum and all efforts to avoid animal suffering were made in accordance with the standards of the Institutional Ethical Committee.

An initial experiment (Exp. I) was realized to monitor stem cell distribution within the normal and QA-lesioned striatum at short (3 weeks) or long ( 8 weeks) time periods following transplantation (see Fig. 2A). To this end, rats were randomly divided into six experimental groups: control rats (injection of vehicle/injection of DMEM; $n=10$ ), vehicle/rNSC-grafted animals $(n=16)$, vehicle/rMSC-grafted animals $(n=16)$, quinolinic acid (QA)-lesioned animals/injection of DMEM $(n=16)$, QA-lesioned/rNSCgrafted animals $(n=16)$ and QA-lesioned/rMSC-grafted animals $(n=16)$. For each injection (vehicle, QA, DMEM or cells), rats were anesthetized with a xylazine/ketamine mixture (Rompun, Bayer; $4.5 \mathrm{mg} / \mathrm{kg}$; Imalgene, Merial; $90 \mathrm{mg} / \mathrm{kg}$ ) and placed in a Kopf stereotaxic frame with the incisor bar set at $-2.3 \mathrm{~mm}$ below the interaural line. QA was prepared in $0.01 \mathrm{M}$ PBS (pH 7.4) as previously described (Bensadoun et al., 2001; Bantubungi et al., 2005). Each rat was injected with either $1 \mu \mathrm{l}$ of QA $(180 \mathrm{nmol}$; Sigma, Belgium) or $1 \mu 1$ of PBS (vehicle) in the right striatum at the following stereotaxic coordinates: AP: $+1.0 \mathrm{~mm}, \mathrm{ML}:-3.5 \mathrm{~mm}$, DV: $-5.0 \mathrm{~mm}$. The injection was performed using a 28 -gauge $10 \mu \mathrm{l}$ Hamilton syringe over a period of $4 \mathrm{~min}$. One week after the QA lesion, all rats were anesthetized again, placed in the stereotaxic apparatus and received unilateral cellular transplants (or only DMEM) in the previously QAlesioned or intact contralateral striatum at two sites: AP: $+1.0 \mathrm{~mm}$, ML: $-3.0 \mathrm{~mm}$, DV: $-4.5 \mathrm{~mm}$ and $-5.0 \mathrm{~mm}$. At both sites, cells were injected in two $2 \mu \mathrm{l}$ deposits over 16 min using a 25 -gauge $10 \mu \mathrm{l}$ Hamilton syringe. Each animal received 50,000 cells at each of the two injection sites $(100,000$ cells in total). Half the animals in each group was sacrificed at 3 weeks post-transplantation (i.e., 4 weeks post-lesion) and the other half at 8 weeks post-transplantation (i.e., 9 weeks post-lesion).

In a second experiment (Exp. II), another 22 rats were injected with vehicle $(n=11)$ or QA $(n=11)$ following the protocol indicated above. Half of each group was sacrificed at 1 week post-lesion for immunohistochemistry and the remaining animals were sacrificed 4 weeks post-lesion for biochemical tests.

We performed control experiments (Exp. III) to ensure the reliability of PKH26 labeling for the monitoring of cell migration in the present experiments. We grafted pre-stained rMSC cells, live or killed before transplantation ( $n=3$ per group). Cells were killed by four successive freeze-thaw cycles (liquid nitrogen was used to freeze the cells, a $37{ }^{\circ} \mathrm{C}$ water bath was used for thawing; personal communication from AlvarezBuylla and Lim). Cells were grafted as described above and the animals killed 3 weeks post-transplantation. At the time of transplantation, a similar number of cells from each group was replated and observed after 5 days to ensure that freeze-thawed cells had been completely killed (see Supplemental data 1).

Ten additional rats (Exp. IV) were used to monitor the effect of the blocking c-kit antibody on the striatal distribution of neural stem cells within the lesioned striatum. QA injections were performed as indicated above. One week after QA injections, all rats were anesthetized again, placed in the stereotaxic apparatus and received rNSCs $(n=10)$ unilateral cellular implants into the previously QA-lesioned striatum at two sites: AP: $+1.0 \mathrm{~mm}$, ML: $-3.0 \mathrm{~mm}$, DV: $-4.5 \mathrm{~mm}$ and $-5.0 \mathrm{~mm}$. At both sites, cells were injected in two $2 \mu \mathrm{l}$ deposits over 16 min using a 25 -gauge $10 \mu \mathrm{l}$ Hamilton syringe. Each animal received approximately 50,000 cells at each of the two injection sites. In half the animals, PKH26-labeled neural stem cells were treated $6 \mathrm{~h}$ prior transplantation with the rat anti-mouse blocking c-kit antibody $(50 \mathrm{ng} / \mathrm{ml}$ in DMEM; CD117 c-kit monoclonal antibody clone ACK45, Pharmingen, Belgium), resuspended in DMEM containing the same concentration of blocking antibody and grafted following the protocol indicated above. All the animals were sacrificed 3 weeks post-lesion for histological evaluation and cell counts.

\section{Brain processing}

After completion of the treatment protocols, animals were injected with an overdose of a xylazine/ketamine mixture and transcardially perfused with $4 \%$ paraformaldehyde in $0.1 \mathrm{M}$ phosphate buffer $(\mathrm{pH}$ 7.4). Brains were removed and post-fixed for $16 \mathrm{~h}$ in the same fixative, washed with $0.01 \mathrm{M}$ PBS and transferred successively for $24 \mathrm{~h}$ each into $10 \%, 20 \%$ and $30 \%$ sucrose solutions in $0.1 \mathrm{M}$ phosphate buffer. Brains were finally embedded in Tissue Tek and frozen using $-40{ }^{\circ} \mathrm{C}$ isopentane. For experiments I and II, serial $16-\mu \mathrm{m}$-thick coronal sections were made using a cryostat at the level of the striatum, and mounted onto poly-L-lysine-coated slides. More precisely, we took all the $16-\mu$ m-thick sections from the planes $\sim+2.5$ to $-1.5 \mathrm{~mm}$ from the bregma. We placed three consecutive sections on the same slide and obtained $\sim 80$ slides per animal, allowing a complete analysis of the region along the antero-posterior axis. For experiment III, $20-\mu \mathrm{m}$-thick serial coronal cryostat sections were obtained and mounted onto poly-L-lysine-coated slides. More precisely, we took all the $20-\mu \mathrm{m}$ thick sections from the planes $\sim+2.5$ to $-1.5 \mathrm{~mm}$ from the bregma. We placed four consecutive sections on the same slide and obtained $\sim 50$ slides per animal.

The protein extracts used in biochemical assays were obtained as follows. The striata of 4-week lesioned rats or vehicle-treated animals were dissected out from 1-mm-thick sections. Care was taken to exclude the SVZ from this preparation. The tissue was then homogenized in M-PER buffer (Pierce, USA) containing protease inhibitors (Complete, Roche Molecular Biochemicals, Germany). Salts were removed from the homogenates and the proteins concentrated using Microcon column (YM-3, Millipore, USA). Finally, protein levels were quantified using the MicroBCA assay (Pierce, USA).

\section{Immunohistochemistry}

Immunohistochemical detection of SCF was performed as follows: sections were incubated in $10 \%$ normal goat serum in PBS containing $0.1 \%$ Triton for $1 \mathrm{~h}$, and then incubated overnight at $4{ }^{\circ} \mathrm{C}$ with rabbit polyclonal anti-SCF (1/250, 1498P, Chemicon, USA). The following day, sections were rinsed, incubated for $1 \mathrm{~h}$ with HRP goat anti-rabbit secondary antibody (1/100, TSA kit, NEN Life Science Products, Belgium), washed three times in $0.01 \mathrm{M}$ PBS and incubated in biotinylated tyramide (TSA kit, NEN Life Science Products, Belgium) for $5 \mathrm{~min}$ at room temperature. The specificity of the SCF staining was assessed by pre-incubating the primary antibody with a 10-fold excess of recombinant mouse SCF immunization peptide (PeproTech, UK). For double labeling, sections were then incubated in $10 \%$ normal horse serum in $0.01 \mathrm{M}$ PBS containing $0.1 \%$ Triton for $1 \mathrm{~h}$ and incubated overnight at $4{ }^{\circ} \mathrm{C}$ with either guinea-pig polyclonal anti-DCX (1/100, AB5910, Chemicon, USA), mouse monoclonal anti-GFAP (1/100, G3893, Sigma, Belgium), mouse monoclonal anti-S100 $\beta$ (1/500; SB6, Abcam), rabbit polyclonal anti-S100 $\beta$ (1/500; Dako), mouse monoclonal anti-NeuN (1/100, MAB377, Chemicon, USA) or mouse monoclonal antiCD11b primary antibodies (1/100; MCA275; Serotec, Belgium). The next day, sections were rinsed in $0.01 \mathrm{M}$ PBS and incubated for $1 \mathrm{~h}$ in biotinylated donkey anti-mouse $\operatorname{IgG}$ or anti-rabbit $\operatorname{IgG}(1 / 200$, Jackson ImmunoResearch, USA) or anti-guinea-pig $\operatorname{IgG}(1 / 200$, Vector Laboratories, USA) for $1 \mathrm{~h}$ at room temperature. Finally, sections were incubated in FITC conjugated with streptavidin (1/200, Vector Laboratories, USA) for $1 \mathrm{~h}$ at room temperature.

For double DCX/GFAP labeling, sections were incubated in $10 \%$ normal horse serum in PBS containing $0.1 \%$ Triton for $1 \mathrm{~h}$ and then overnight at $4{ }^{\circ} \mathrm{C}$ with guinea pig polyclonal anti-DCX (1/5000, AB5910, Chemicon, USA), and the next day with mouse monoclonal anti-GFAP (1/100, G3893, Sigma, Belgium). The TSA-signal amplification system (NEN-Life Science, Belgium) and Cy3-conjugated IgG system were employed as described above.

For double Nestin/GFAP and Nestin/DCX labeling, immunohistochemistry was performed as follows: the sections were incubated in $10 \%$ normal goat serum in PBS containing $0.1 \%$ Triton for $1 \mathrm{~h}$ and then overnight at $4{ }^{\circ} \mathrm{C}$ with mouse monoclonal anti-nestin (1/100, rat403, Pharmingen, Belgium), and the 
next day with rabbit polyclonal anti-GFAP (1/100, G9269, Sigma, Belgium) or guinea-pig polyclonal anti-DCX (1/100, AB5910, Chemicon, USA). The TSA-signal amplification system (NEN-Life Science, Belgium) and Cy3conjugated IgG system were employed as described above.

Triple labeling for SCF/DCX/GFAP was performed as follows: the sections were incubated in $10 \%$ normal goat serum in PBS containing $0.1 \%$ Triton for $1 \mathrm{~h}$ and then overnight at $4{ }^{\circ} \mathrm{C}$ with rabbit polyclonal anti-SCF $(1 / 250,1498 \mathrm{P}$, Chemicon, USA). The next day, the SCF signal was revealed using the TSA-signal amplification system (NEN-Life Science, Belgium). We then incubated the sections with guinea-pig polyclonal antiDCX (1/100, AB5910, Chemicon, USA) and mouse monoclonal antiGFAP $\left(1 / 100\right.$, G3893, Sigma, Belgium) overnight at $4{ }^{\circ} \mathrm{C}$. Detection was realized using, respectively, Cy3- and Cy5-conjugated IgGs.

For the PCNA labeling, sections were incubated in citrate buffer $(300 \mathrm{ml})$ and heated with a microwave ( $4 \mathrm{~min}$ at $800 \mathrm{~W}$ and $2 \times 5 \mathrm{~min}$ at $400 \mathrm{~W}$ ). Next, the sections were incubated in $10 \%$ normal horse serum in PBS containing $0.1 \%$ Triton-X100 for $1 \mathrm{~h}$ and then overnight at $4{ }^{\circ} \mathrm{C}$ with mouse monoclonal anti-PCNA (1/500, sc-56, Santa Cruz, USA). The signal was revealed using the TSA-signal amplification system (NEN-Life Science, Belgium) as described above (Chemicon, USA).

In all cases except the triple labeling, sections were counterstained with the nuclear dyes Hoechst or TOTO-3 iodide (Molecular Probes, USA) and then mounted with FluorSave reagent (Calbiochem, France).

\section{Hoechst and TOTO-3 iodide counterstaining}

For Hoechst (Molecular Probes, USA) nuclear counterstaining, sections were incubated for $5 \mathrm{~min}$ in $160 \mu \mathrm{M}$ Hoechst in $0.01 \mathrm{M}$ PBS. Sections were then rinsed in 0.01 M PBS. For TOTO-3 iodide (Molecular Probes, USA) nuclear counterstaining, sections were incubated for $2 \mathrm{~h}$ in $1 \mu \mathrm{M}$ TOTO-3 iodide in $0.01 \mathrm{M}$ PBS and rinsed as above. All sections were mounted with FluorSave reagent (Calbiochem, France).

\section{Cytochrome oxidase staining}

Frozen sections mounted on poly-L-lysine-coated slides were incubated for $3 \times 10 \mathrm{~min}$ in phosphate buffer $(0.1 \mathrm{M}, \mathrm{pH} 7.4)$. Thereafter, slides were incubated overnight in the dark in phosphate buffer $(0.1 \mathrm{M}, \mathrm{pH}$ 7.4) containing $4 \%$ sucrose, $0.05 \%$ Diaminobenzidine (DAB, Sigma, Belgium) and $0.02 \%$ cytochrome $c$ (Sigma, Belgium). Finally, slides were rinsed in phosphate buffer (0.1 M, pH 7.4) and mounted with DPX. QA-induced lesions appeared as a blank area in these sections (Fig. 2B).

\section{Laser-scanning confocal microscopy (LSCM)}

The immunofluorescent sections or pre-grafted cells were analyzed with a laser-scanning confocal microscope (LSM 510 Meta Confocal, Zeiss, Germany).

\section{Rostro-caudal distribution of grafted cells}

The distance of migration of the transplanted cells from the injection site was defined rostro-caudally as the length between the first section where PKH26-positive cells were present in the striatum and the first section where no more PKH26-positive cells could be seen in the striatum. This was achieved by the observation of all frozen, unmounted sections from each rat under the fluorescent microscope. This allowed us to keep the section available for further histological processing such as cytochrome oxidase staining, counting and immunohistochemistry.

\section{Cell counts}

The number of PKH26-labeled rMSCs and rNSCs in the striatum was counted in coronal sections using a semi-automated method (Bizat et al.,
2003, Arango et al., 2006). Coronal sections $400 \mu \mathrm{m}$ apart containing the striatum were scanned with a $20 \times$ objective, using a Zeiss Axioplan2 imaging microscope motorized for $X, Y$ and $Z$ displacements. For each section, an area encompassing the entire region displaying PKH26 fluorescence (from 0.48 to $5.1 \mathrm{~mm}^{2}$ ) was acquired using the acquisition system (Morphostar 5.12, IMSTAR, Paris). This corresponds to 8 to 81 digitized images of contiguous $278.8 \mu \mathrm{m} \times 227.6 \mu \mathrm{m}$ fields of view (i.e., $0.063 \mathrm{~mm}^{2}$ ). Image pixels were $0.40 \mu \mathrm{m} \times 0.40 \mu \mathrm{m}$. Section fluorescence (excitation) was similar for all acquisitions and homogeneity was automatically corrected using blank images. Images were automatically segmented for the quantification and $(X, Y)$ localization of fluorescent objects (PHK26-containing cells), using the same parameters defining fluorescence intensity threshold and object size filters. Since fluorescence intensity was slightly variable from one section to another, we normalized the analysis by defining the light intensity threshold at 3 standard deviations above the average light intensity detected over the entire section. With this procedure, PHK26-labeled objects with an apparent cross-sectional area greater than $2 \mu \mathrm{m}^{2}$ were reliably detected. For all images, objects touching one of the $X$ or $Y$ borders of the fields of view were eliminated. We counted from 30 to 5404 objects/region displaying PHK26 fluorescence (depending on the section in question) and the apparent cross-sectional area was recorded in each case. The estimated total number of PHK26 objects $(\mathrm{Ne})$ was corrected for bias resulting from section thickness $(20 \mu \mathrm{m})$ using the Abercrombie factor (Clarke, 1992). This was possible since most PHK26 labeling was round (mean rotundity index $\sim$ ) with an isotropic orientation in the striatum. This factor $(A)$ was estimated to be 0.8196 , based on the mean object height determined from observation of the objects detected in each experimental group. The corrected number of PHK26 positive objects (Nc) per section was calculated as $\mathrm{Nc}=A \times \mathrm{Ne}$. The total number of stained cells per striatum was calculated by first estimating the volume of the striatum from the number of sections obtained per hemisphere (see previous paragraph), and then multiplying by Nc.

\section{In vitro c-kit activity test}

To test c-kit activity, rMSCs and rNSCs were starved of fetal bovine serum (rMSCs) or B27/N2/EGF (rNSCs) for $4 \mathrm{~h}$ and stimulated for $20 \mathrm{~min}$ with $100 \mathrm{ng} / \mathrm{ml}$ of recombinant rat SCF (PeproTech, UK) or with purified protein extracts from 4-week QA-lesioned or vehicle rats $(30 \mu \mathrm{g}$ in $1 \mathrm{ml}$ of culture medium). The cells were harvested and washed in cold $0.01 \mathrm{M}$ PBS and proteins were extracted at $4{ }^{\circ} \mathrm{C}$ for $1 \mathrm{~h}$ with shaking, using a solubilization buffer containing $80 \mathrm{mM}$ Tris- $\mathrm{HCl}, 150 \mathrm{mM} \mathrm{NaCl}, 20 \mathrm{mM}$ EDTA pH 7.5, $200 \mathrm{mM} \mathrm{NaF}, 1 \%$ Brij, $4 \mathrm{mM}$ vanadate, $5 \mathrm{mM} \mathrm{Na}_{2} \mathrm{PO}_{4} .10 \mathrm{H}_{2} \mathrm{O}, 10 \mu \mathrm{M}$ okadaic acid and protease inhibitors (Complete, Roche Molecular Biochemicals, Germany). Extracts were cleared by centrifugation at $13,000 \mathrm{rpm}$ for 30 min at $4{ }^{\circ} \mathrm{C}$. The protein extracts were then removed and stored at $-20^{\circ} \mathrm{C}$ until analysis. Protein concentrations were quantified using MicroBCA Protein Assay (Pierce, USA).

\section{Western blotting}

Western blotting experiments were performed as we have previously described (Blum et al., 2002). Equal amounts of protein $(40 \mu \mathrm{g})$ were denatured in Laemmli buffer at $100{ }^{\circ} \mathrm{C}$, loaded onto $6 \%$ SDSpolyacrylamide gels (for phospho-c-kit and c-kit detection) or 12\% SDSpolyacrylamide gels (for phospho-p44/42 MAPK and p44/42 MAPK detection) and transferred onto nitrocellulose at a constant current of $25 \mathrm{~V}$ for $1 \mathrm{~h}$ (Trans-blot, semi-dry transfer cell, Biorad, Belgium). The primary antibodies used were goat anti-c-kit (1/500, sc-1494, Santa Cruz, USA), rabbit anti-phospho-c-kit (1/500, 3391, Cell Signaling, USA), rabbit antip44/42 MAPK (1/2000, 9102, Cell Signaling, USA) and mouse antiphospho-p44/42 MAPK (1/500, 9101, Cell Signaling, USA). Following overnight incubation at $4{ }^{\circ} \mathrm{C}$, membranes were washed and incubated with biotin-labeled secondary antibodies, i.e., donkey anti-rabbit $\operatorname{IgG}(1 / 2000)$, anti-mouse IgG (1/1000) or anti-goat IgGs $(1 / 10000)$, and then with avidinbiotin-peroxidase complex (Vectastain $\mathrm{ABC}$ kit, Vector Laboratories). 
Signals were detected using the chemiluminescent ECL reagent (PerkinElmer, Life Technologies).

In vitro migration assay

Briefly, recombinant rat SCF (100 ng/ml; PeproTech, UK) diluted in DMEM or purified protein extracted from 4-week QA-lesioned or vehicle rats $(30 \mu \mathrm{g}$ in $1 \mathrm{ml}$ of culture medium) were incubated in the lower compartment of 12 -well ( $12 \mu \mathrm{m}$ pores) or 48 -well ( $8 \mu \mathrm{m}$ pores) chemotaxis chambers for rMSCs and rNSCs, respectively (Costar, USA). Assays were performed in the presence or the absence of a c-kit blocking antibody ( $5 \mathrm{ng} / \mathrm{ml}$; rat anti-mouse CD117 c-kit monoclonal antibody clone ACK45, Pharmingen, Belgium), added to cells $30 \mathrm{~min}$ prior to the addition of recombinant SCF or protein extracts. A total of $10^{6}$ cells $/ \mathrm{ml}$ of DMEM per well ( $n=12$ per condition) was plated in the upper half of the chamber. Cells were separated from the chemoattractant by a polyvinylpyrrolidone-free polycarbonate filter. The chambers were incubated in a humidified incubator containing $5 \% \mathrm{CO}_{2}$ for $24 \mathrm{~h}$ at $37{ }^{\circ} \mathrm{C}$. Cells which migrated through the pores were counted in five random squares per well. It is worth noting that in our paradigm, in order to avoid interference with other substances, the medium used for testing was DMEM only, explaining why rMSCs did not re-attach and rNSCs did not form spheres once they had passed through the micropores (see Supplemental data 4). Results were expressed as the mean \pm SEM of the values obtained in these fields.

\section{Proliferation assay}

Cell proliferation was measured using an MTS (3-(4,5-dimethylthiazol2-yl)-5-(3-carboxymethoxyphenyl)-2-(4-sulfophenyl)-2 $H$-tetrazolium, inner salt) reduction assay (Aqueous One Solution cell proliferation assay, Promega, Belgium). MTS reduction is an indicator of cell number. Briefly, $2.5 \times 10^{4} \mathrm{rMSCs}$ or rNSCs were seeded ( $n=6$ per condition) into each well of 6-well culture plates with $2.5 \mathrm{ml}$ of culture medium supplemented with $10 \mathrm{ng} / \mathrm{ml}$ recombinant rat SCF (PeproTech, UK) for five days. Cells were assessed at day 5 by adding $625 \mu \mathrm{l}$ of dye solution into each well followed by incubation for $2 \mathrm{~h}$ at $37{ }^{\circ} \mathrm{C}$. The absorbance of the final solution in each well was then measured at $490 \mathrm{~nm}$ with a $96-w e l l$ plate reader.

\section{Statistics}

Results were expressed as means \pm SEM. Comparisons among groups were made using one-way analysis of variance (ANOVA) followed by an LSD-Fisher post hoc test, Bonferroni post hoc test or unpaired Student's $t$ test using Statistica Software (Statsoft, France).

\section{Acknowledgments}

We thank Katerin Backers, Didier Communi, Katia Coulonval, Raphaël Hourez, Dong Mei Wang, Els Pastijn, Jean-Yves Springael and Jean-Marie Vanderwinden for their help. This article was prepared with editorial help from Gap Junction (France). KB and SW-G were recipients of Televie fellowships. BR is a Senior Research Associate of the FNRS. KB is supported by ANR. DB is an INSERM investigator. This work was supported by Televie (Belgium) (SNS, BR), FNRS (Belgium) (SNS, BR, DB), FMRE (Belgium) (SNS, BR), Van Buuren Foundation (Belgium) (SNS, $\mathrm{DB}$ ), Action de Recherche Concertée (Communauté Française de Belgique, SNS, BR), Hereditary Disease Foundation (USA) (DB), the Ligue Belge de la Sclérose en Plaques (BR) and the Fonds Charcot (BR). This work was also supported by the CNRS and the CEA.

\section{Appendix A. Supplementary data}

Supplementary data associated with this article can be found, in the online version, at doi:10.1016/j.mcn.2007.11.001.

\section{References}

Arango, M., Holbert, S., Zala, D., Brouillet, E., Pearson, J., Regulier, E., Thakur, A.K., Aebischer, P., Wetzel, R., Deglon, N., Neri, C., 2006. CA150 expression delays striatal cell death in overexpression and knockin conditions for mutant huntingtin neurotoxicity. J. Neurosci. 26, 4649-4659.

Arvidsson, A., Collin, T., Kirik, D., Kokaia, Z., Lindvall, O., 2002. Neuronal replacement from endogenous precursors in the adult brain after stroke. Nat. Med. 8, 963-970.

Ashley, DM., Bol, S.J., Waugh, C., Kannourakis, G., 1993. A novel approach to the measurement of different in vitro leukaemic cell growth parameters: the use of PKH GL fluorescent probes. Leuk. Res. 17, 873-882.

Bachoud-Levi, A.C., Remy, P., Nguyen, J.P., Brugieres, P., Lefaucheur, J.P., Bourdet, C., Baudic, S., Gaura, V., Maison, P., Haddad, B., Boisse, M.F., Grandmougin, T., Jeny, R., Bartolomeo, P., Dalla Barba, G., Degos, J.D., Lisovoski, F., Ergis, A.M., Pailhous, E., Cesaro, P., Hantraye, P., Peschanski, M., 2000. Motor and cognitive improvements in patients with Huntington's disease after neural transplantation. Lancet 356, 1975-1979.

Bachoud-Levi, A.C., Gaura, V., Brugieres, P., Boisse, M.F., Maison, P., Baudic, S., Ribeiro, M.J., Bourdet, C., Remy, P., Cesaro, P., Hantraye, P., Peschanski, M., 2006. Effect of fetal neural transplants in patients with Huntington's disease 6 years after surgery: a long term follow-up study. Lancet Neurol. 5, 303-309.

Bantubungi, K., Jacquard, C., Greco, A., Pintor, A., Chtarto, A., Tai, K., Galas, M.C., Tenenbaum, L., Deglon, N., Popoli, P., Minghetti, L., Brouillet, E., Brotchi, J., Levivier, M., Schiffmann, S.N., Blum, D., 2005. Minocycline in phenotypic models of Huntington's disease. Neurobiol. Dis. 18, 206-217.

Beal, M.F., Kowall, N.W., Ellison, D.W., Mazurek, M.F., Swartz, K.J., Martin, J.B., 1986. Replication of the neurochemical characteristics of Huntington's disease by quinolinic acid. Nature $321,168-171$.

Belmadani, A., Tran, P.B., Ren, D., Miller, R.J., 2006. Chemokines regulate the migration of neural progenitors to sites of neuroinflammation. J. Neurosci. 26, 3182-3191.

Bensadoun, J.C., de Almeida, L.P., Dreano, M., Aebischer, P., Deglon, N., 2001. Neuroprotective effect of interleukin-6 and IL6/IL6R chimera in the quinolinic acid rat model of Huntington's syndrome. Eur. J. Neurosci. 14, $1753-1761$.

Bizat, N., Hermel, J.M., Boyer, F., Jacquard, C., Creminon, C., Ouary, S., Escartin, C., Hantraye, P., Kajewski, S., Brouillet, E., 2003. Calpain is a major cell death effector in selective striatal degeneration induced in vivo by 3-nitropropionate: implications for Huntington's disease. J. Neurosci. 23, 5020-5030.

Bjorklund, A., Stenevi, U., 1984. Intracerebral neural implants: neuronal replacement and reconstruction of damaged circuitries. Annu. Rev. Neurosci. 7, 279-308.

Blum, D., Gall, D., Galas, M.C., d'Alcantara, P., Bantubungi, K., Schiffmann, S.N., 2002. The adenosine A1 receptor agonist adenosine amine congener exerts a neuroprotective effect against the development of striatal lesions and motor impairments in the 3-nitropropionic acid model of neurotoxicity. J. Neurosci. 22, 9122-9133.

Blum, D., Hourez, R., Galas, M.C., Popoli, P., Schiffmann, S.N., 2003. Adenosine receptors and Huntington's disease: implications for pathogenesis and therapeutics. Lancet Neurol. 2, 366-374.

Bosch, M., Pineda, J.R., Sunol, C., Petriz, J., Cattaneo, E., Alberch, J., Canals, J.M., 2004. Induction of GABAergic phenotype in a neural stem cell line for transplantation in an excitotoxic model of Huntington's disease. Exp. Neurol. 190, 42-58. 
Brown, J.P., Couillard-Despres, S., Cooper-Kuhn, C.M., Winkler, J., Aigner, L., Kuhn, H.G., 2003. Transient expression of doublecortin during adult neurogenesis. J. Comp. Neurol. 467, 1-10.

Clarke, P.G., 1992. How inaccurate is the Abercrombie correction factor for cell counts? Trends Neurosci. 15, 211-212.

Collin, T., Arvidsson, A., Kokaia, Z., Lindvall, O., 2005. Quantitative analysis of the generation of different striatal neuronal subtypes in the adult brain following excitotoxic injury. Exp. Neurol. 195, 71-80.

Cooper, O., Isacson, O., 2004. Intrastriatal transforming growth factor alpha delivery to a model of Parkinson's disease induces proliferation and migration of endogenous adult neural progenitor cells without differentiation into dopaminergic neurons. J. Neurosci. 24, 8924-8931.

Couillard-Despres, S., Winner, B., Schaubeck, S., Aigner, R., Vroemen, M., Weidner, N., Bogdahn, U., Winkler, J., Kuhn, H.G., Aigner, L., 2005. Doublecortin expression levels in adult brain reflect neurogenesis. Eur. J. Neurosci. 21, 1-14.

Croitoru-Lamoury, J., Guillemin, G.J., Dormont, D., Brew, B.J., 2003. Quinolinic acid up-regulates chemokine production and chemokine receptor expression in astrocytes. Adv. Exp. Med. Biol. 527, 37-45.

Curtis, M.A., Penney, E.B., Pearson, A.G., Roon-Mom, W.M., Butterworth, N.J., Dragunow, M., Connor, B., Faull, R.L., 2003. Increased cell proliferation and neurogenesis in the adult human Huntington's disease brain. Proc. Natl. Acad. Sci. U. S. A. 100, 9023-9027.

Dhandapani, K.M., Wade, F.M., Wakade, C., Mahesh, V.B., Brann, D.W., 2005. Neuroprotection by stem cell factor in rat cortical neurons involves Akt and NF-kB. J. Neurochem. 95, 9-19.

Eglitis, M.A., Dawson, D., Park, K.W., Mouradian, M.M., 1999. Targeting of marrow-derived astrocytes to the ischemic brain. Neuroreport 10, $1289-1292$.

Emsley, J.G., Mitchell, B.D., Kempermann, G., Macklis, J.D., 2005. Adult neurogenesis and repair of the adult CNS with neural progenitors, precursors, and stem cells. Prog. Neurobiol. 75, 321-341.

Erlandsson, A., Larsson, J., Forsberg-Nilsson, K., 2004. Stem cell factor is a chemoattractant and a survival factor for CNS stem cells. Exp. Cell Res. 301, 201-210.

Geloso, M.C., Giannetti, S., Cenciarelli, C., Budoni, M., Casalbore, P., Maira, G., Michetti, F., 2007. Transplantation of foetal neural stem cells into the rat hippocampus during trimethyltin-induced neurodegeneration. Neurochem. Res. 32 (12), 2054-2061.

Glaspy, J., 1996. Clinical applications of stem cell factor. Curr. Opin. Hematol. 3 , 223-229.

Greene, J.G., Greenamyre, J.T., 1996. Bioenergetics and glutamate excitotoxicity. Prog. Neurobiol. 48, 613-634.

Guidetti, P., Luthi-Carter, R.E., Augood, S.J., Schwarcz, R., 2004. Neostriatal and cortical quinolinate levels are increased in early grade Huntington's disease. Neurobiol. Dis. 17, 455-461.

Hassan, H.T., Zander, A., 1996. Stem cell factor as a survival and growth factor in human normal and malignant hematopoiesis. Acta Haematol. 95, 257-262.

Hill, W.D., Hess, D.C., Martin-Studdard, A., Carothers, J.J., Zheng, J., Hale, D., Maeda, M., Fagan, S.C., Carroll, J.E., Conway, S.J., 2004. SDF-1 (CXCL12) is upregulated in the ischemic penumbra following stroke: association with bone marrow cell homing to injury. J. Neuropathol. Exp. Neurol. 63, 84-96.

Imitola, J., Raddassi, K., Park, K.I., Mueller, F.J., Nieto, M., Teng, Y.D., Frenkel, D., Li, J., Sidman, R.L., Walsh, C.A., Snyder, E.Y., Khoury, S.J., 2004. Directed migration of neural stem cells to sites of CNS injury by the stromal cell-derived factor 1alpha/CXC chemokine receptor 4 pathway. Proc. Natl. Acad. Sci. U. S. A. 101, 18117-18122.

Isacson, O., 2003. The production and use of cells as therapeutic agents in neurodegenerative diseases. Lancet Neurol. 2N, 417-424.

Jin, K., Mao, X.O., Sun, Y., Xie, L., Greenberg, D.A., 2002. Stem cell factor stimulates neurogenesis in vitro and in vivo. J. Clin. Invest. 110, 311-319.

Jin, K., Peel, A.L., Mao, X.O., Xie, L., Cottrell, B.A., Henshall, D.C., Greenberg, D.A., 2004. Increased hippocampal neurogenesis in Alzheimer's disease. Proc. Natl. Acad. Sci. U. S. A. 101, 343-347.
Kendall, A.L., Rayment, F.D., Torres, E.M., Baker, H.F., Ridley, R.M., Dunnett, S.B., 1998. Functional integration of striatal allografts in a primate model of Huntington's disease. Nat. Med. 4, 727-729.

Kelly, S., Bliss, T.M., Shah, A.K., Sun, G.H., Ma, M., Foo, W.C., Masel, J., Yenari, M.A., Weissman, I.L., Uchida, N., Palmer, T., Steinberg, G.K., 2004. Transplanted human fetal neural stem cells survive, migrate, and differentiate in ischemic rat cerebral cortex. Proc. Natl. Acad. Sci. U. S. A. 101, 11839-11844.

Kokaia, Z., Lindvall, O., 2003. Neurogenesis after ischaemic brain insults. Curr. Opin. Neurobiol. 13, 127-132.

Kordower, J.H., Chen, E.Y., Winkler, C., Fricker, R., Charles, V., Messing, A., Mufson, E.J., Wong, S.C., Rosenstein, J.M., Bjorklund, A., Emerich, D.F., Hammang, J., Carpenter, M.K., 1997. Grafts of EGF-responsive neural stem cells derived from GFAP-hNGF transgenic mice: trophic and tropic effects in a rodent model of Huntington's disease. J. Comp. Neurol. 387, 96-113.

Lim, D.A., Fishell, G.J., Alvarez-Buylla, A., 1997. Postnatal mouse subventricular zone neuronal precursors can migrate and differentiate within multiple levels of the developing neuraxis. Proc. Natl. Acad. Sci. U. S. A. $94,14832-14836$.

Lindvall, O., Kokaia, Z., Martinez-Serrano, A., 2004. Stem cell therapy for human neurodegenerative disorders - how to make it work. Nat. Med. $10, \mathrm{~S} 42-\mathrm{S} 50$

Linnekin, D., 1999. Early signaling pathways activated by c-Kit in hematopoietic cells. Int. J. Biochem. Cell Biol. 31, 1053-1074.

Mahmood, A., Lu, D., Wang, L., Li, Y., Lu, M., Chopp, M., 2001. Treatment of traumatic brain injury in female rats with intravenous administration of bone marrow stromal cells. Neurosurgery 49, 1196-1203.

Martinez-Serrano, A., Bjorklund, A., 1996. Protection of the neostriatum against excitotoxic damage by neurotrophin-producing, genetically modified neural stem cells. J. Neurosci. 16, 4604-4616.

Matsui, Y., Zsebo, K.M., Hogan, B.L., 1990. Embryonic expression of a haematopoietic growth factor encoded by the Sl locus and the ligand for c-kit. Nature 347, 667-669.

McBride, J.L., Behrstock, S.P., Chen, E.Y., Jakel, R.J., Siegel, I., Svendsen, C.N., Kordower, J.H., 2004. Human neural stem cell transplants improve motor function in a rat model of Huntington's disease. J. Comp. Neurol. 475, 211-219.

McNiece, I.K., Briddell, R.A., 1995. Stem cell factor. J. Leukoc. Biol. 58, $14-22$.

Modo, M., Stroemer, R.P., Tang, E., Patel, S., Hodges, H., 2002. Effects of implantation site of stem cell grafts on behavioral recovery from stroke damage. Stroke 33, 2270-2278.

Nakao, N., Itakura, T., 2000. Fetal tissue transplants in animal models of Huntington's disease: the effects on damaged neuronal circuitry and behavioral deficits. Prog. Neurobiol. 61, 313-338.

Nishino, H., Hida, H., Takei, N., Kumazaki, M., Nakajima, K., Baba, H., 2000. Mesencephalic neural stem (progenitor) cells develop to dopaminergic neurons more strongly in dopamine-depleted striatum than in intact striatum. Exp. Neurol. 164, 209-214.

Ohta, H., Tohda, A., Nishimune, Y., 2003. Proliferation and differentiation of spermatogonial stem cells in the $\mathrm{w} / \mathrm{wv}$ mutant mouse testis. Biol. Reprod. 69, 1815-1821.

Palfi, S., Conde, F., Riche, D., Brouillet, E., Dautry, C., Mittoux, V., Chibois, A., Peschanski, M., Hantraye, P., 1998. Fetal striatal allografts reverse cognitive deficits in a primate model of Huntington disease. Nat. Med. 4, 963-966.

Peschanski, M., Bachoud-Levi, A.C., Hantraye, P., 2004. Integrating fetal neural transplants into a therapeutic strategy: the example of Huntington's disease. Brain 127, 1219-1228.

Reynolds, B.A., Weiss, S., 1992. Generation of neurons and astrocytes from isolated cells of the adult mammalian central nervous system. Science $255,1707-1710$.

Rieske, P., Azizi, A., Augelli, B., Gaughan, J., Krynska, B., 2007. A population of human brain parenchymal cells express markers of glial, neuronal and early neural cells and differentiate into cells of neuronal and glial lineages. Eur. J. Neurosci. 25, 31-37. 
Ryu, J.K., Kim, J., Cho, S.J., Hatori, K., Nagai, A., Choi, H.B., Lee, M.C., McLarnon, J.G., Kim, S.U., 2004. Proactive transplantation of human neural stem cells prevents degeneration of striatal neurons in a rat model of Huntington disease. Neurobiol. Dis. 16, 68-77.

Sotelo, C., Alvarado-Mallart, R.M., 1987. Reconstruction of the defective cerebellar circuitry in adult Purkinje cell degeneration mutant mice by Purkinje cell replacement through transplantation of solid embryonic implants. Neuroscience 20, 1-22.

Sun, L., Lee, J., Fine, H.A., 2004. Neuronally expressed stem cell factor induces neural stem cell migration to areas of brain injury. J. Clin. Invest. $113,1364-1374$

Tai, Y.T., Svendsen, C.N., 2004. Stem cells as a potential treatment of neurological disorders. Curr. Opin. Pharmacol. 4, 98-104.

Tattersfield, A.S., Croon, R.J., Liu, Y.W., Kells, A.P., Faull, R.L., Connor, B., 2004. Neurogenesis in the striatum of the quinolinic acid lesion model of Huntington's disease. Neuroscience 127, 319-332.

Wandzioch, E., Edling, C.E., Palmer, R.H., Carlsson, L., Hallberg, B., 2004. Activation of the MAP kinase pathway by c-Kit is PI-3 kinase dependent in hematopoietic progenitor/stem cell lines. Blood 104, $51-57$.

Watts, C., Dunnett, S.B., 1998. Effects of severity of host striatal damage on the morphological development of intrastriatal transplants in a rodent model of Huntington's disease: implications for timing of surgical intervention. J. Neurosurg. 89, 267-274.

Wichterle, H., Garcia-Verdugo, J.M., Herrera, D.G., Alvarez-Buylla, A., 1999. Young neurons from medial ganglionic eminence disperse in adult and embryonic brain. Nat. Neurosci. 2, 461-466.

Williams, D.E., Lyman, S.D., 1991. Characterization of the gene-product of the Steel locus. Prog. Growth Factor Res. 3, 235-242.

Wislet-Gendebien, S., Hans, G., Leprince, P., Rigo, J.M., Moonen, G., Rogister, B., 2005. Plasticity of cultured mesenchymal stem cells: switch from nestin-positive to excitable neuron-like phenotype. Stem Cells 23, 392-402.

Wislet-Gendebien, S., Leprince, P., Moonen, G., Rogister, B., 2003. Regulation of neural markers nestin and GFAP expression by cultivated bone marrow stromal cells. J. Cell Sci. 116, 3295-3302. 